\title{
Mapping Precipitation Changes
}

\author{
Xianghui Kong, Xiaoxin Wang, Huopo Chen, Aihui Wang, Dan Wan, \\ Lianlian Xu, Yue Miao, Ju Huang, Yang Liu, Ruiheng Xie, Yue Chen, \\ and Xianmei Lang
}

\section{Introduction}

Compared to the observed changes in temperature, the changes in precipitation show more uncertainty (Hartmann et al. 2013). The IPCC AR5 indicated that anthropogenic forcing has contributed to a global-scale intensification of heavy precipitation since the second half of the twentieth century (IPCC 2013) and the intensity of daily precipitation increases more under the higher warming scenarios (Weber et al. 2018).

To achieve a comprehensive understanding of changes in precipitation in the future, this section initiatively assesses

Authors: Xianghui Kong, Xiaoxin Wang, Huopo Chen, Aihui Wang, Dan Wan, Lianlian Xu, Yue Miao, Ju Huang, Yang Liu, Ruiheng Xie, Yue Chen, Xianmei Lang.

Map Designers: Yelin Sun, Tian Liu, Fanya Shi, Jing'ai Wang, Ying Wang.

Language Editor: Aihui Wang.

X. Kong · H. Chen · A. Wang $(\bowtie) \cdot$ D. Wan · L. Xu · Y. Miao · J. Huang · Y. Liu · R. Xie

Institute of Atmospheric Physics, Nansen-Zhu International

Research Centre, Chinese Academy of Sciences, Beijing, 100029, China

e-mail: wangaihui@mail.iap.ac.cn

X. Wang

Climate Change Research Center, Institute of Atmospheric Physics, Chinese Academy of Sciences, Beijing, 100029, China

L. Xu

School of Atmospheric Sciences, Sun Yat-Sen University, Zhuhai, 519082, China

Y. Chen

College of Atmospheric Sciences, Lanzhou University, Lanzhou, 730000, China

\section{Lang}

International Center for Climate and Environment Sciences, Institute of Atmospheric Physics, Chinese Academy of Sciences, Beijing, 100029, China the change of precipitation characteristics, such as mean amount, variability, and extremes under three greenhouse gas emissions scenarios, including Representative Concentration Pathway (RCP) 2.6, RCP4.5, and RCP8.5.

\section{Data}

Same as the daily maximum and minimum temperature data, the global daily precipitation data were also retrieved from the NEX-GDDP dataset under RCP4.5 and RCP8.5 from 21 climate models in the Coupled Model Intercomparison Project Phase 5 (CMIP5) (https://www.nccs.nasa.gov/ services/data-collections/land-based-products/nex-gddp).

Furthermore, the precipitation data from 13 models in CMIP5 under the RCP2.6 scenario have also been downscaled by the Institute of Atmospheric Physics (IAP) Chinese Academy of Sciences (CAS) (Xu and Wang 2019). This dataset covers all grids between $60^{\circ} \mathrm{S}$ and $90^{\circ} \mathrm{N}$ global land area. The spatial resolution of the data for all maps is $0.25^{\circ}(\sim 25 \mathrm{~km} \times 25 \mathrm{~km})$.

\section{Method}

The precipitation extremes cover three time periods, including the historical period (1986-2005, denoted as the 2000s), and two future periods 2016-2035 (2030s) and 2046-2065 (2050s). Summer represents June-July-August (JJA), and winter is December and January-February (DJF) of the following year. 
Total precipitation in wet days $(\mathrm{Pr})$ is defined as the 20-year mean of summation of all daily precipitation amount $\geq 1 \mathrm{~mm} \mathrm{~d}^{-1}$ during the 2000s, 2030s, and 2050s. The $P r$ change $(\%)$ is defined as:

$$
\begin{aligned}
& P r_{\text {change }}=100 \% \times\left(P r_{2030 \mathrm{~s}}-P r_{2000 \mathrm{~s}}\right) / P r_{2000 \mathrm{~s}} \\
& P r_{\text {change }}=100 \% \times\left(P r_{2050 \mathrm{~s}}-P r_{2000 \mathrm{~s}}\right) / P r_{2000 \mathrm{~s}}
\end{aligned}
$$

The inter-model uncertainty of $\operatorname{Pr}$ (ensemble spread) is defined as the standard deviation of the $P r_{\text {change }}$ across all models.

Precipitation variability is defined as the standard deviation of $\operatorname{Pr}$ during three different periods. The change of precipitation variability during the 2030s and 2050s is calculated similarly as Eqs. (1) and (2), respectively. The inter-model uncertainty is the standard deviation of the precipitation variability across all models.

Precipitation extreme indices, including RXIday, RX5day, and $R 10 \mathrm{~mm}$, are adopted from the Expert Team on Climate Change Detection and Indices (ETCCDI, see Klein Tank et al. (2009) and Zhang et al. (2011)).
RXIday is the maximum 1-day precipitation amount $(\mathrm{mm} /$ day). $R 10 \mathrm{~mm}$ is the number of days when daily precipitation amount $\geq 10 \mathrm{~mm}$. RX5day is the maximum consecutive 5-day precipitation. The definition of RXIday change, RX5day change, and R10mm change and their inter-model uncertainty are similarly defined as those in Eqs. (1) and (2).

\section{Major Findings}

Nine regions were selected following Giorgi and Bi (2005) to quantitatively compare the changes of precipitation under the three greenhouse gas emissions scenarios. These regions are sensitive to global warming (Xu et al. 2019). Figures 1, 2, 3, 4 and 5 show the area-weighted average annual total precipitation in wet days, precipitation variability, annual maximum 1-day precipitation (RX1D), annual days of daily precipitation equal to or greater than $10 \mathrm{~mm}(\mathrm{R} 10 \mathrm{~mm})$, and annual maximum consecutive 5-day precipitation (RX5D), respectively. Generally, the changes in precipitation depend on the greenhouse gas emissions scenario and the region.

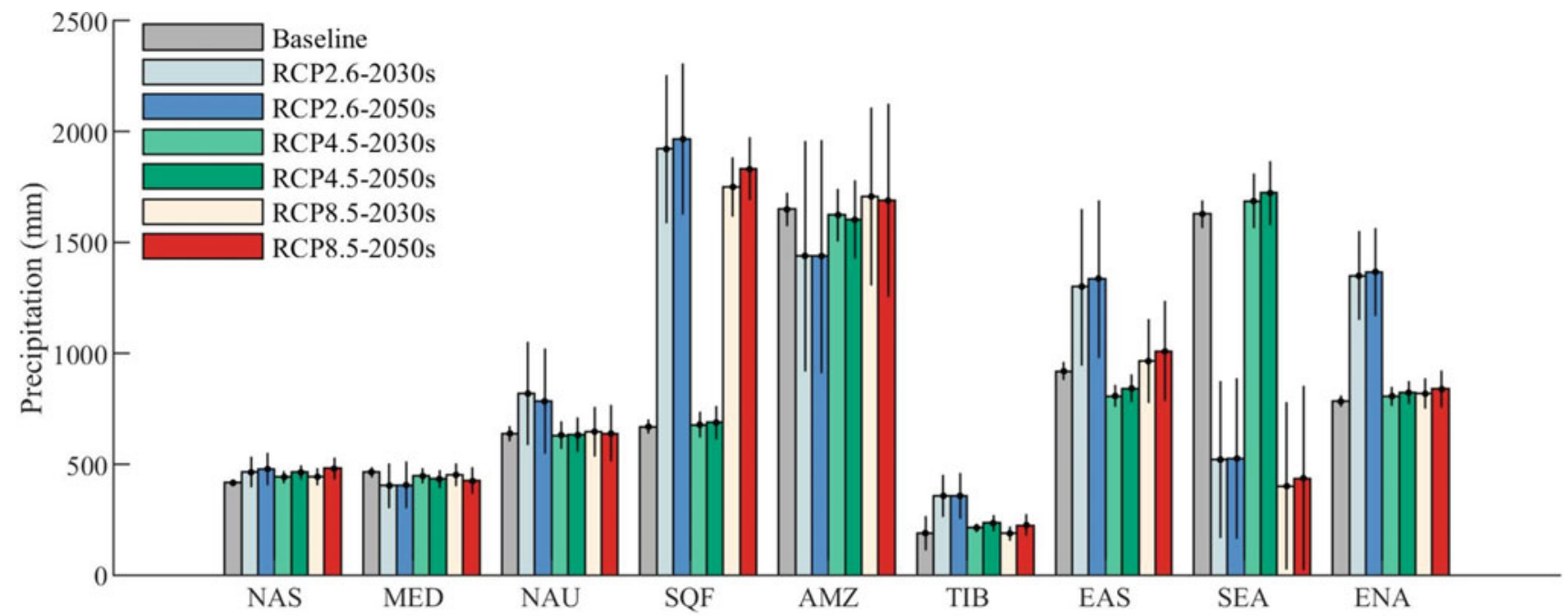

Fig. 1 Annual total precipitation in wet days (unit: $\mathrm{mm}$ ) in nine regions under different Representative Concentration Pathway (RCP) scenarios. The error bar represents the one standard deviation across all selected models-13 general circulation models (GCMs) (RCP2.6) and 21 GCMs (RCP4.5 and RCP8.5). NAS, MED, NAU, SQF, AMZ, TIB, EAS, SEA, and ENA represent North Asia $\left(47-70^{\circ} \mathrm{N}\right.$, $\left.60.5-180.5^{\circ} \mathrm{E}\right)$, Mediterranean Basin $\left(30-47^{\circ} \mathrm{N}, 10.5^{\circ} \mathrm{W}-37.5^{\circ} \mathrm{E}\right)$,
Northern Australia $\left(28-10^{\circ} \mathrm{S}, 109.5-155.5^{\circ} \mathrm{E}\right)$, South Equatorial Africa $\left(26-0^{\circ} \mathrm{S}, 0.5-55.5^{\circ} \mathrm{E}\right)$, Amazon Basin $\left(20^{\circ} \mathrm{S}-10^{\circ} \mathrm{N}, 78.5-34.5^{\circ} \mathrm{W}\right)$, Tibet $\left(30-47^{\circ} \mathrm{N}, 80.5-104.5^{\circ} \mathrm{E}\right)$, East Asia $\left(20-47^{\circ} \mathrm{N}, 104.5-140.5^{\circ} \mathrm{E}\right)$, Southeast Asia $\left(10^{\circ} \mathrm{S}-20^{\circ} \mathrm{N}, 100.5-150.5^{\circ} \mathrm{E}\right)$, and Eastern North America $\left(25-50^{\circ} \mathrm{N}, 85.5-60.5^{\circ} \mathrm{W}\right)$, respectively. The regional division follows Giorgi and $\mathrm{Bi}(2005)$ 


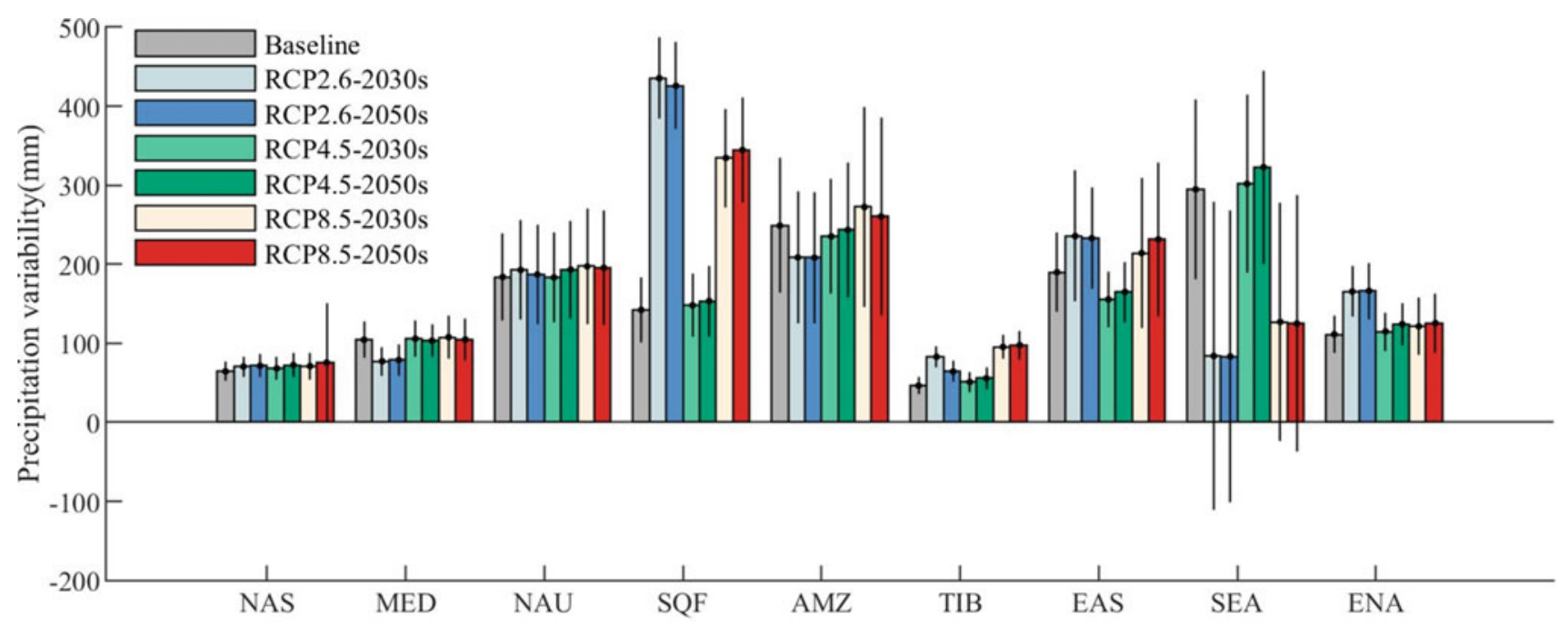

Fig. 2 Variability of annual total precipitation in wet days (unit: $\mathrm{mm}$ ) in nine regions under different Representative Concentration Pathway (RCP) scenarios. The error bar represents the one standard deviation

across all selected models. Region abbreviations are the same as in Fig. 1

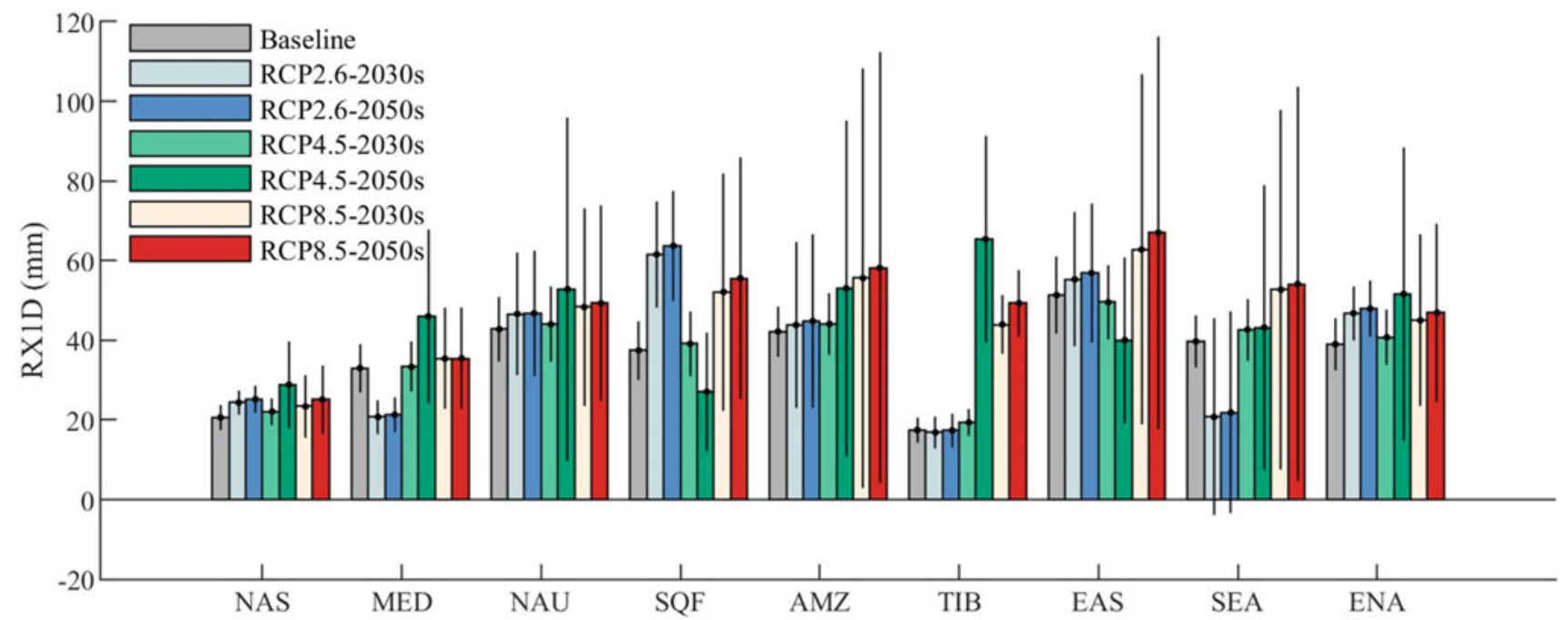

Fig. 3 Annual maximum 1-day precipitation (unit: $\mathrm{mm}$ ) in nine regions under different Representative Concentration Pathway (RCP) scenarios. The error bar represents the one standard deviation across all selected models. Region abbreviations are the same as in Fig. 1 


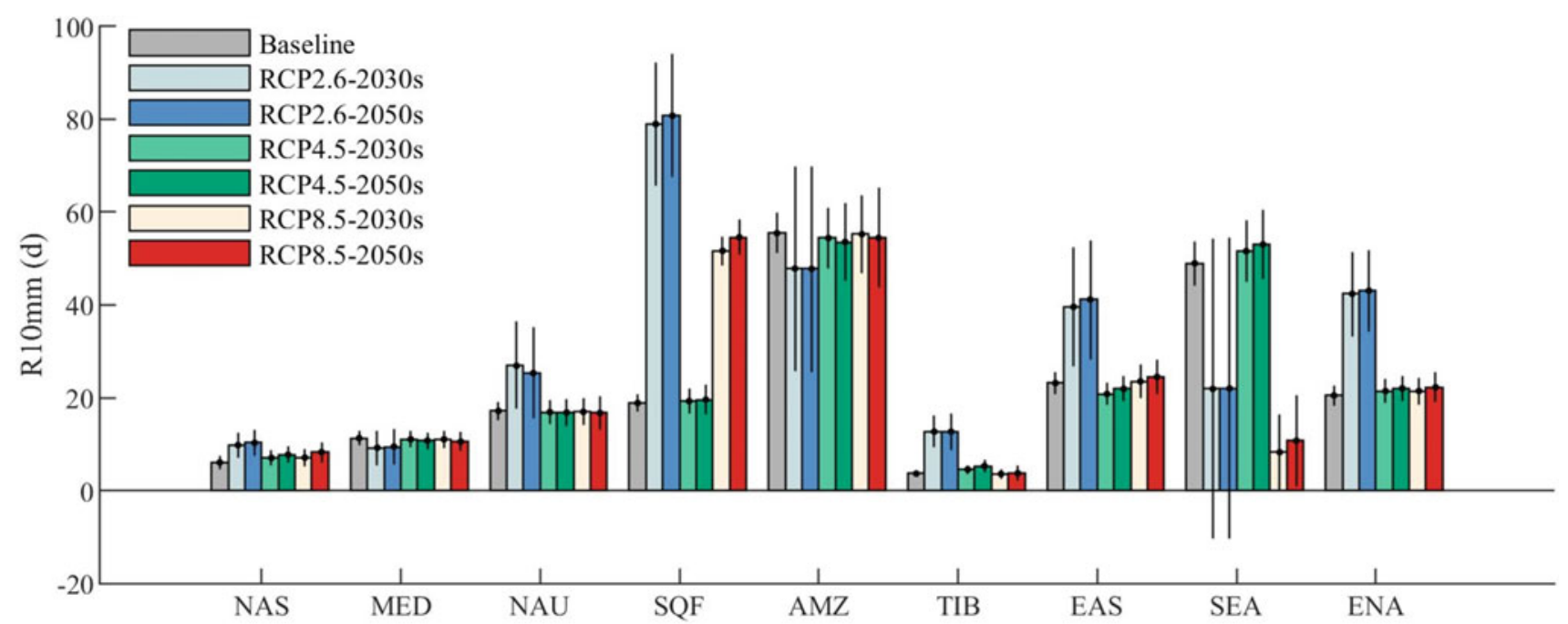

Fig. 4 Annual days of daily precipitation equal to or greater than $10 \mathrm{~mm}$ (unit: d) in nine regions under different Representative one standard deviation across all selected models. Region abbreviations Concentration Pathway (RCP) scenarios. The error bar represents the are the same as in Fig. 1

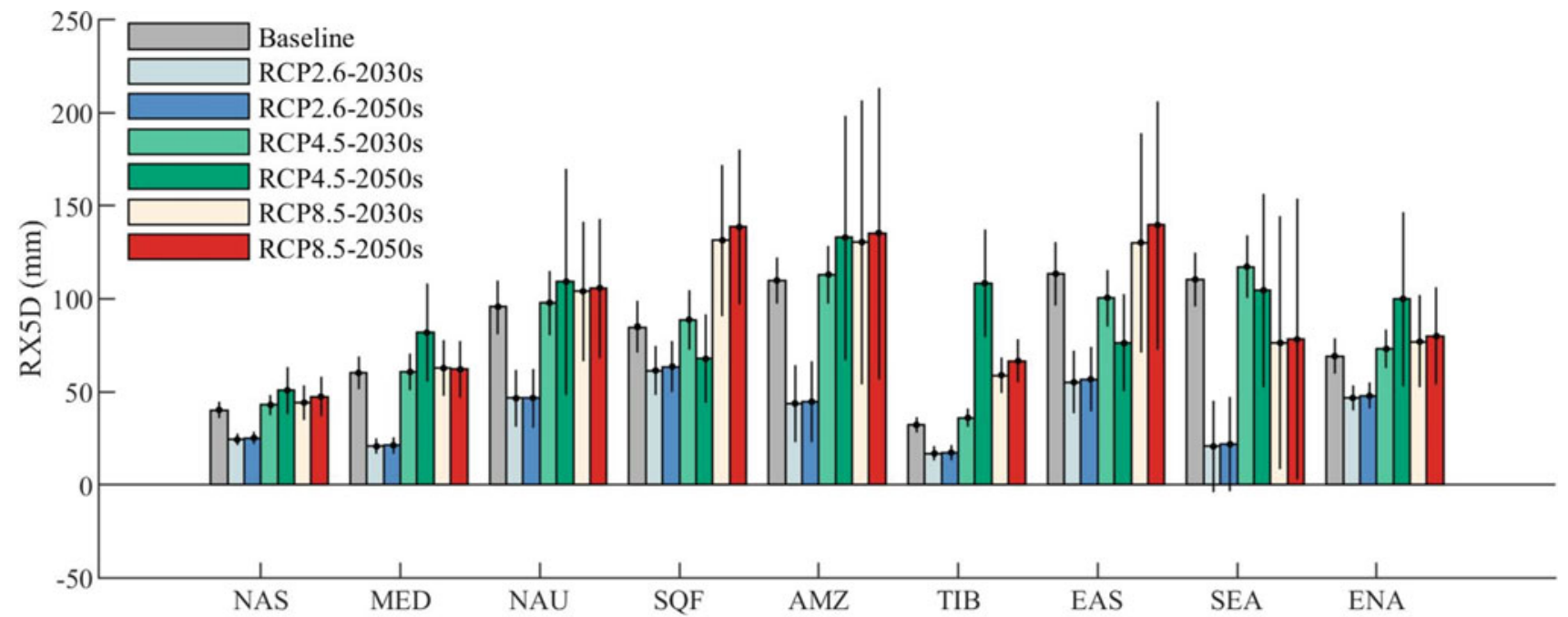

Fig. 5 Annual maximum consecutive 5-day precipitation (unit: $\mathrm{mm}$ ) in nine regions under different Representative Concentration Pathway (RCP) scenarios. The error bar represents the one standard deviation

across all selected models. Region abbreviations are the same as in Fig. 1 


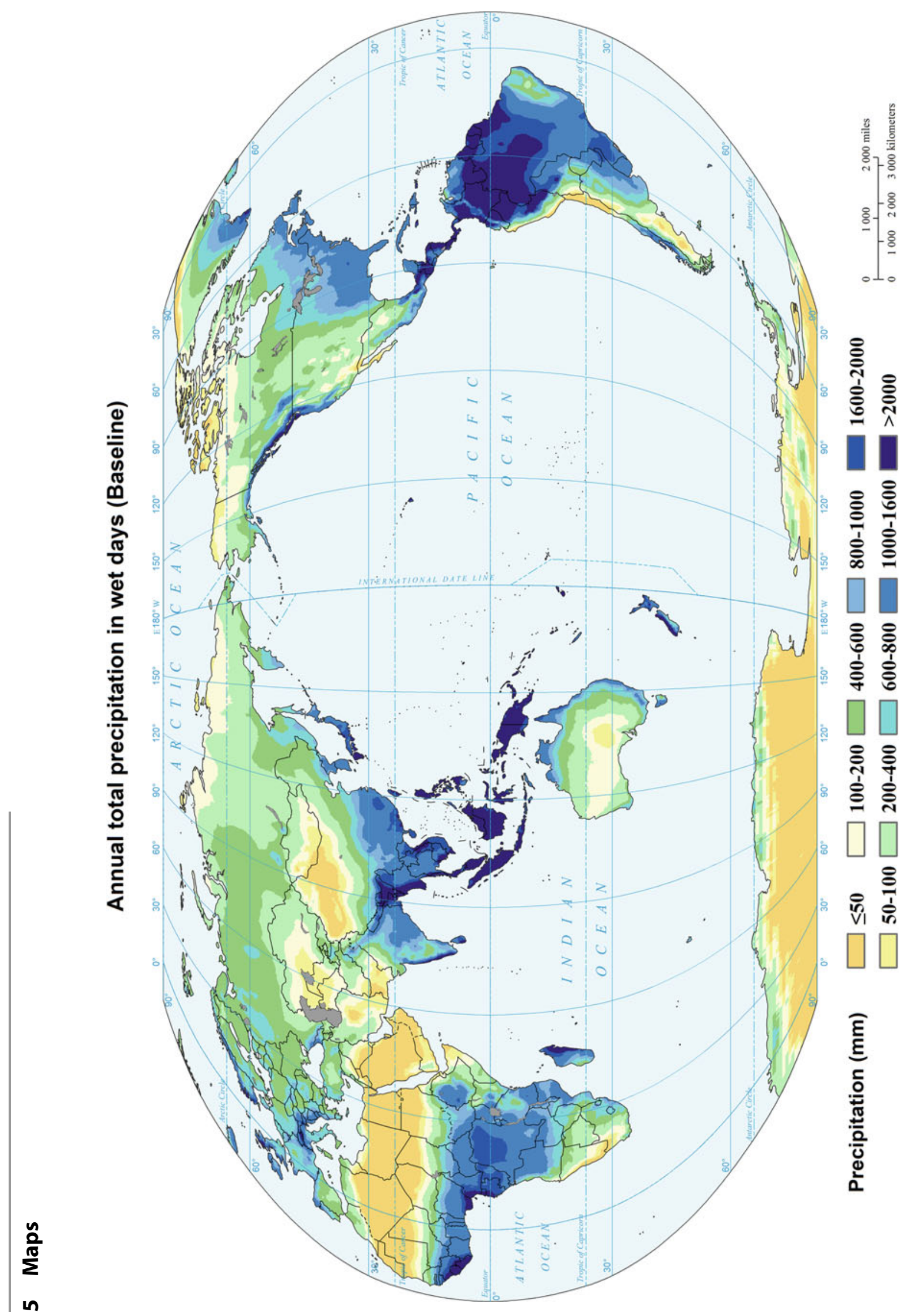


Annual total precipitation in wet days (2030s, RCP2.6)

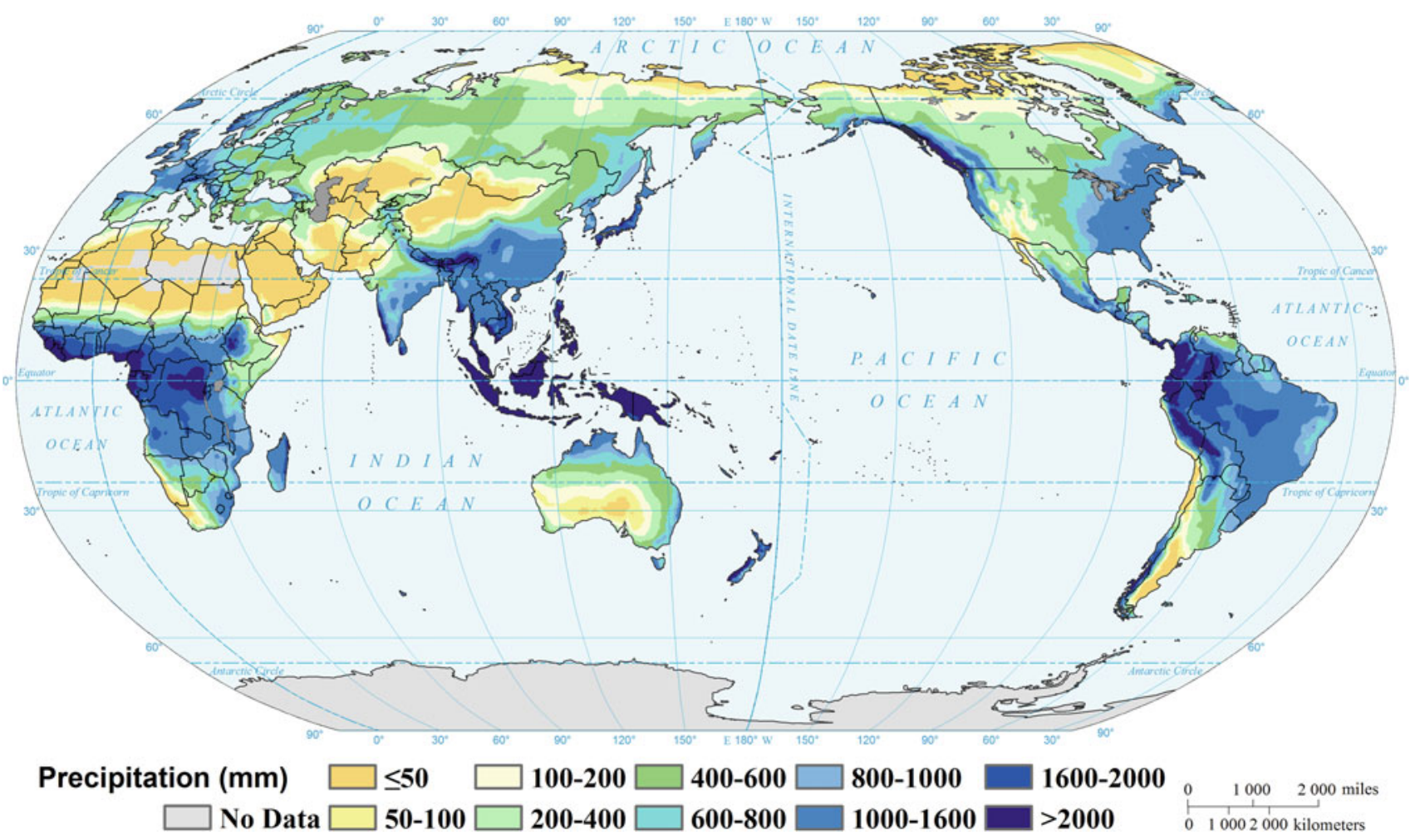

Annual total precipitation in wet days (2030s, RCP4.5)

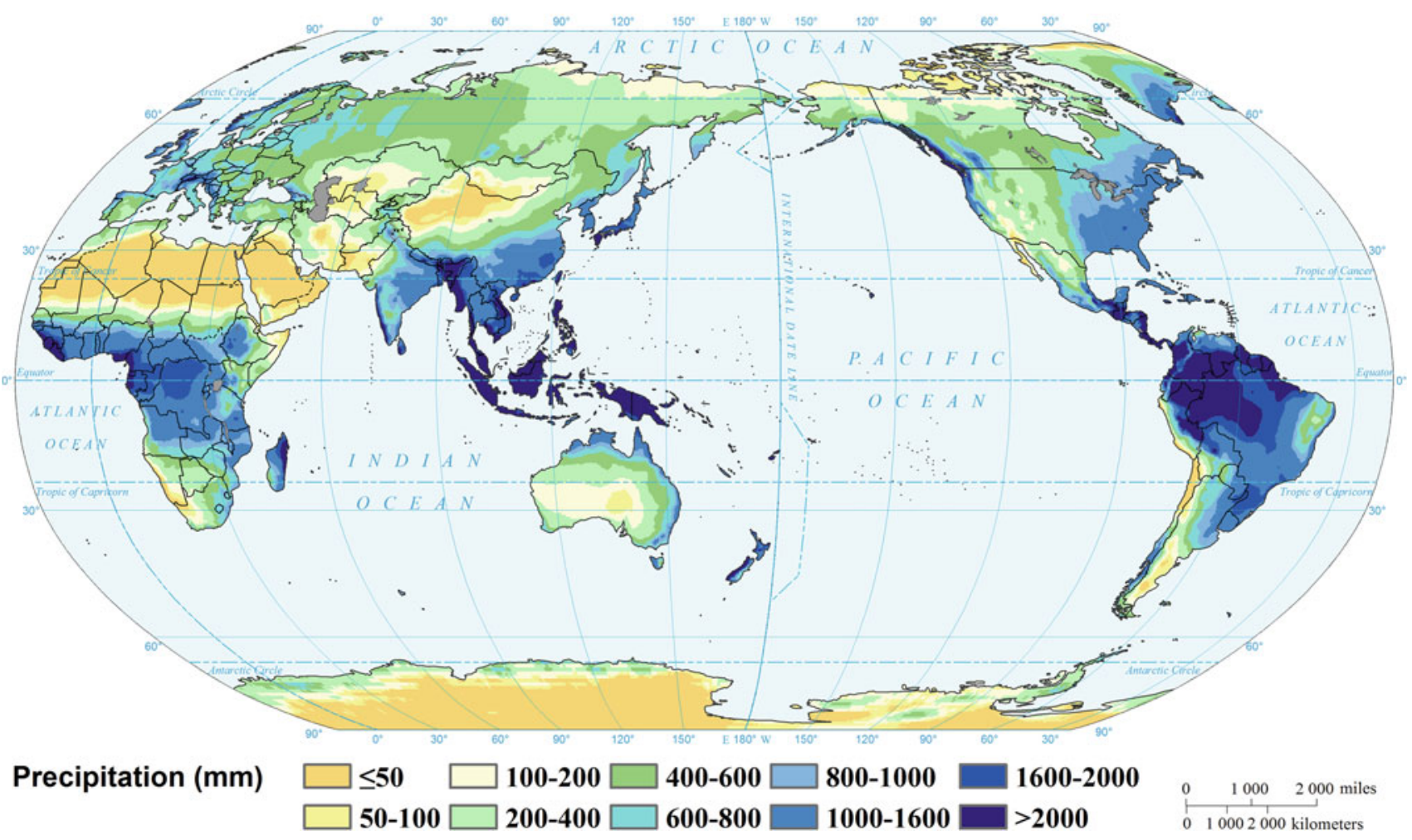


Annual total precipitation in wet days (2030s, RCP8.5)

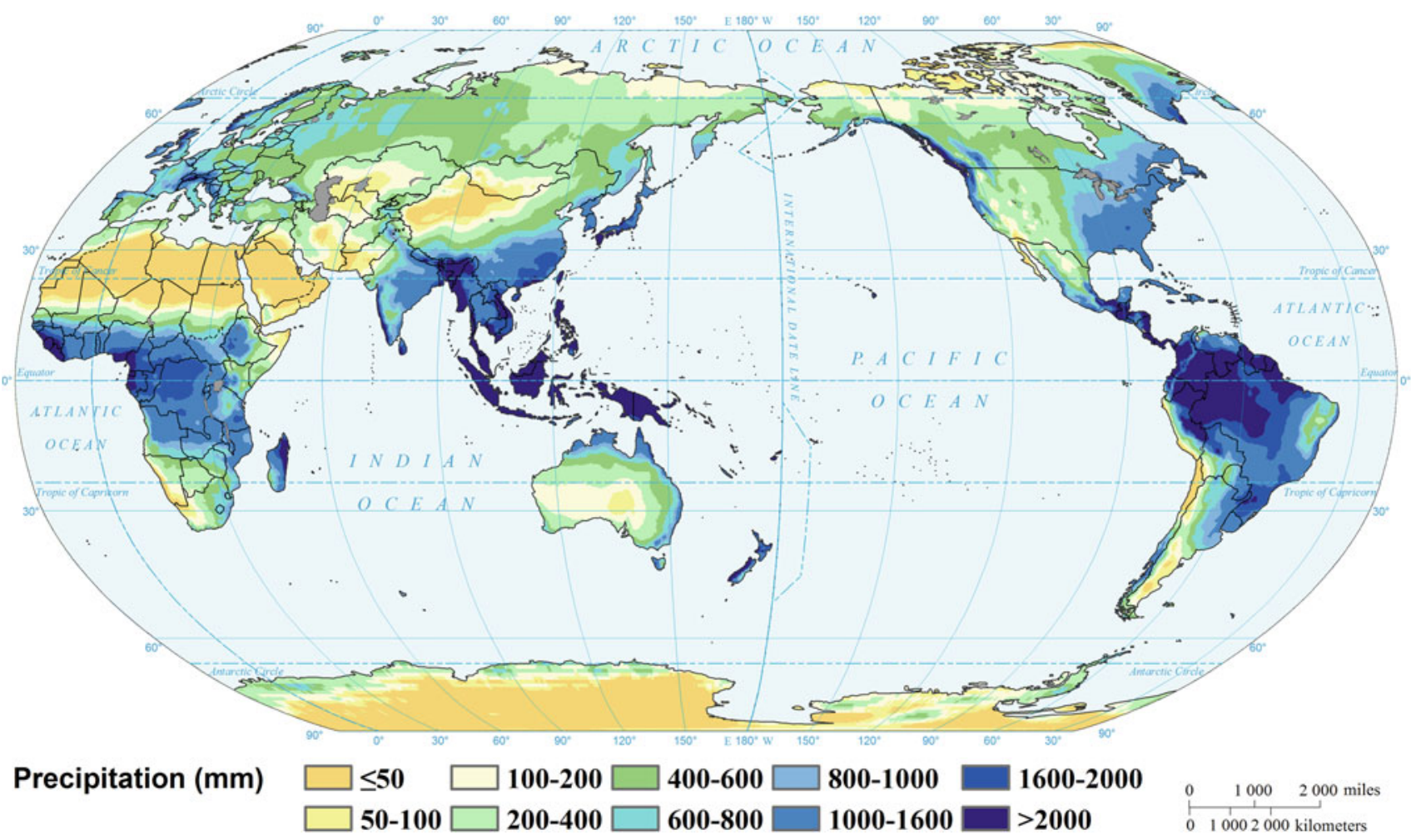

Annual total precipitation in wet days (2050s, RCP2.6)

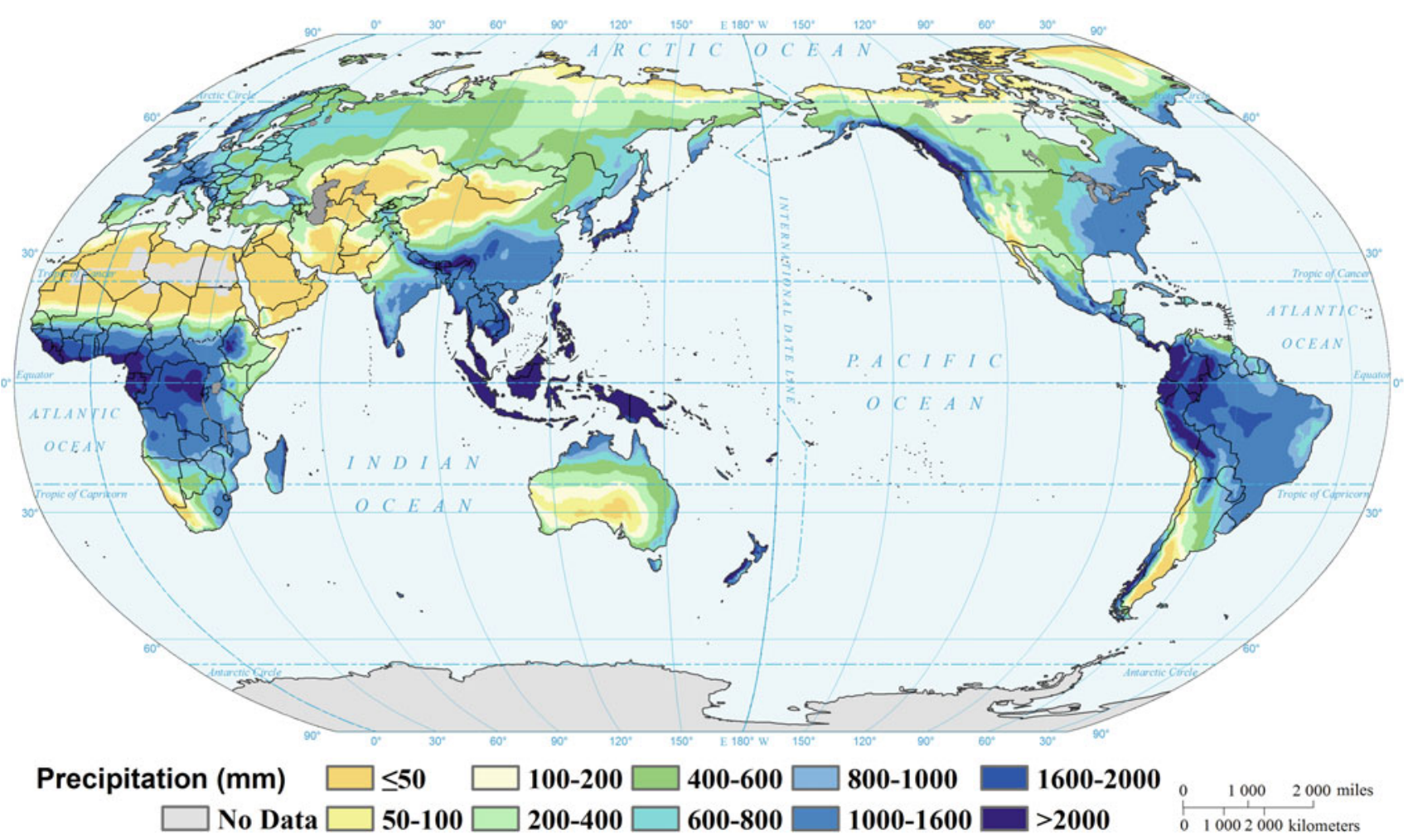


Annual total precipitation in wet days (2050s, RCP4.5)

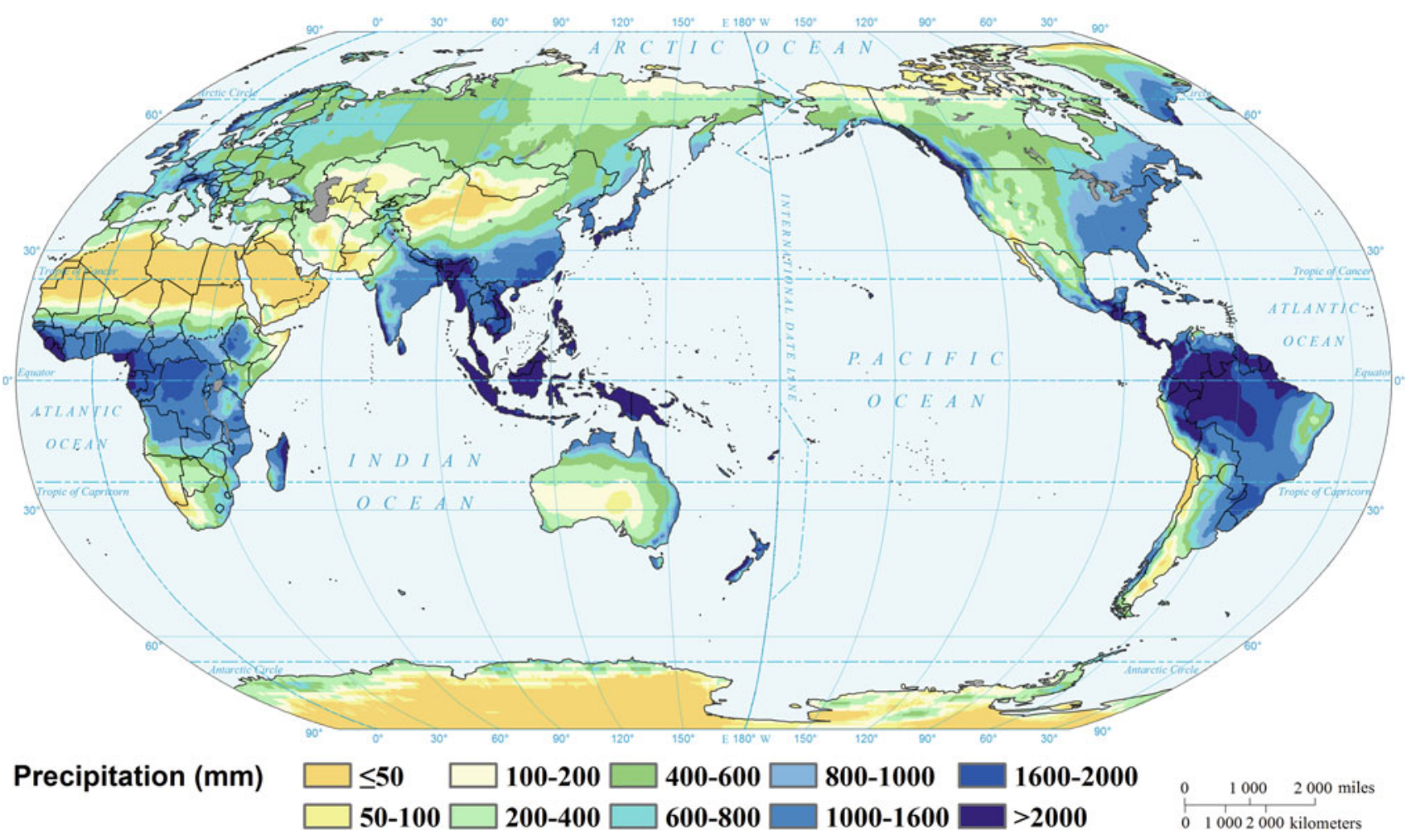

Annual total precipitation in wet days (2050s, RCP8.5)

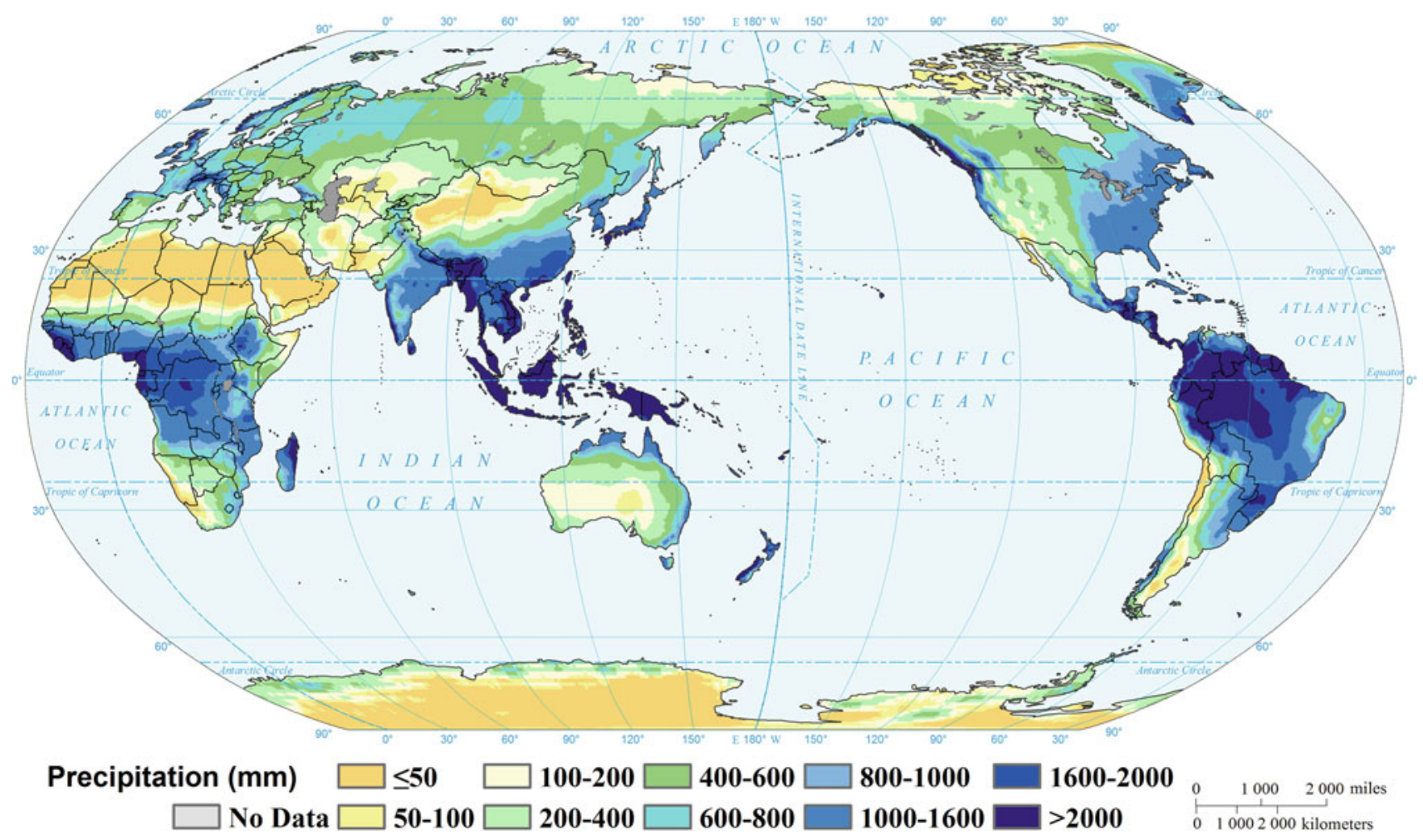




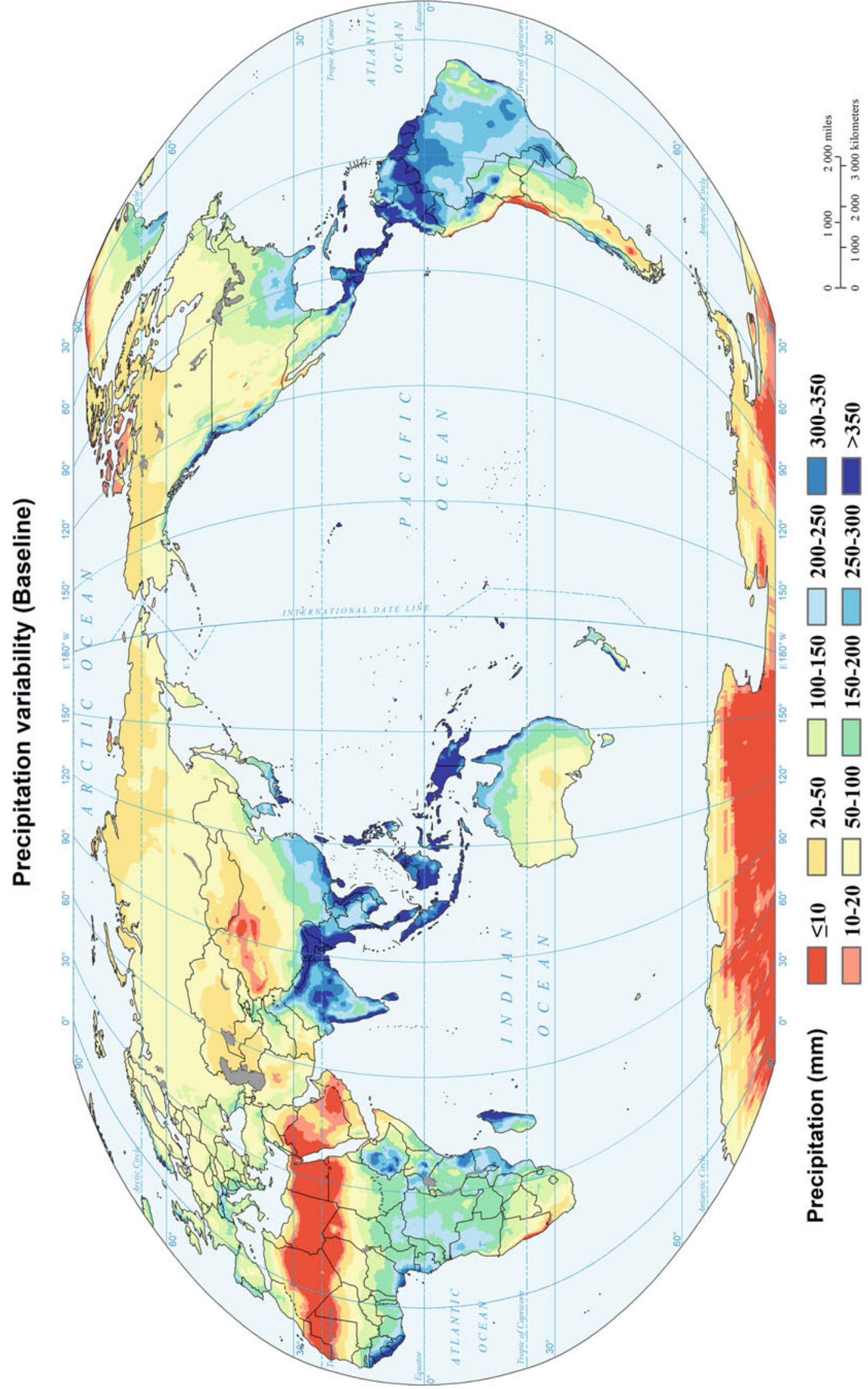




\section{Precipitation variability (2030s, RCP2.6)}

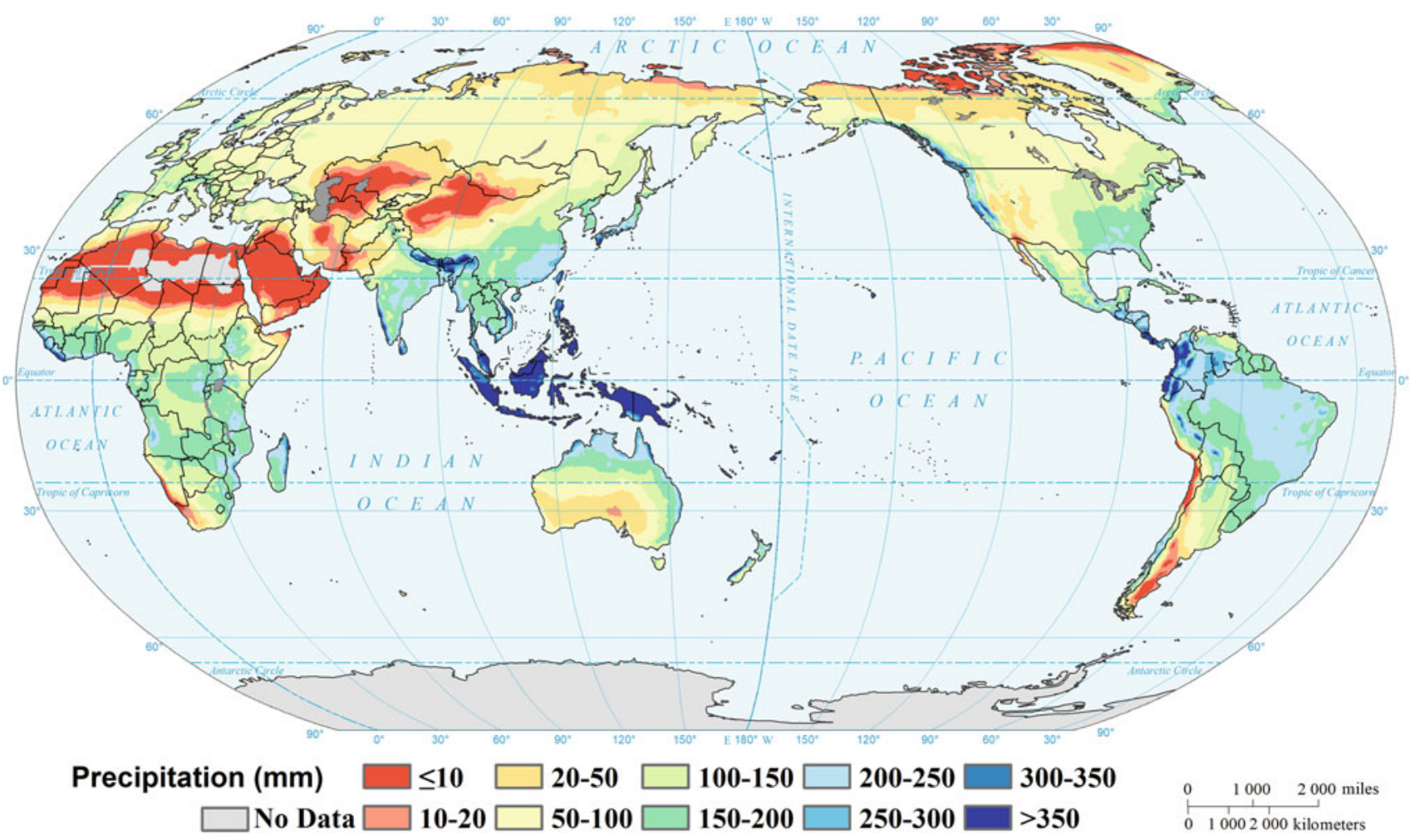

Precipitation variability (2030s, RCP4.5)

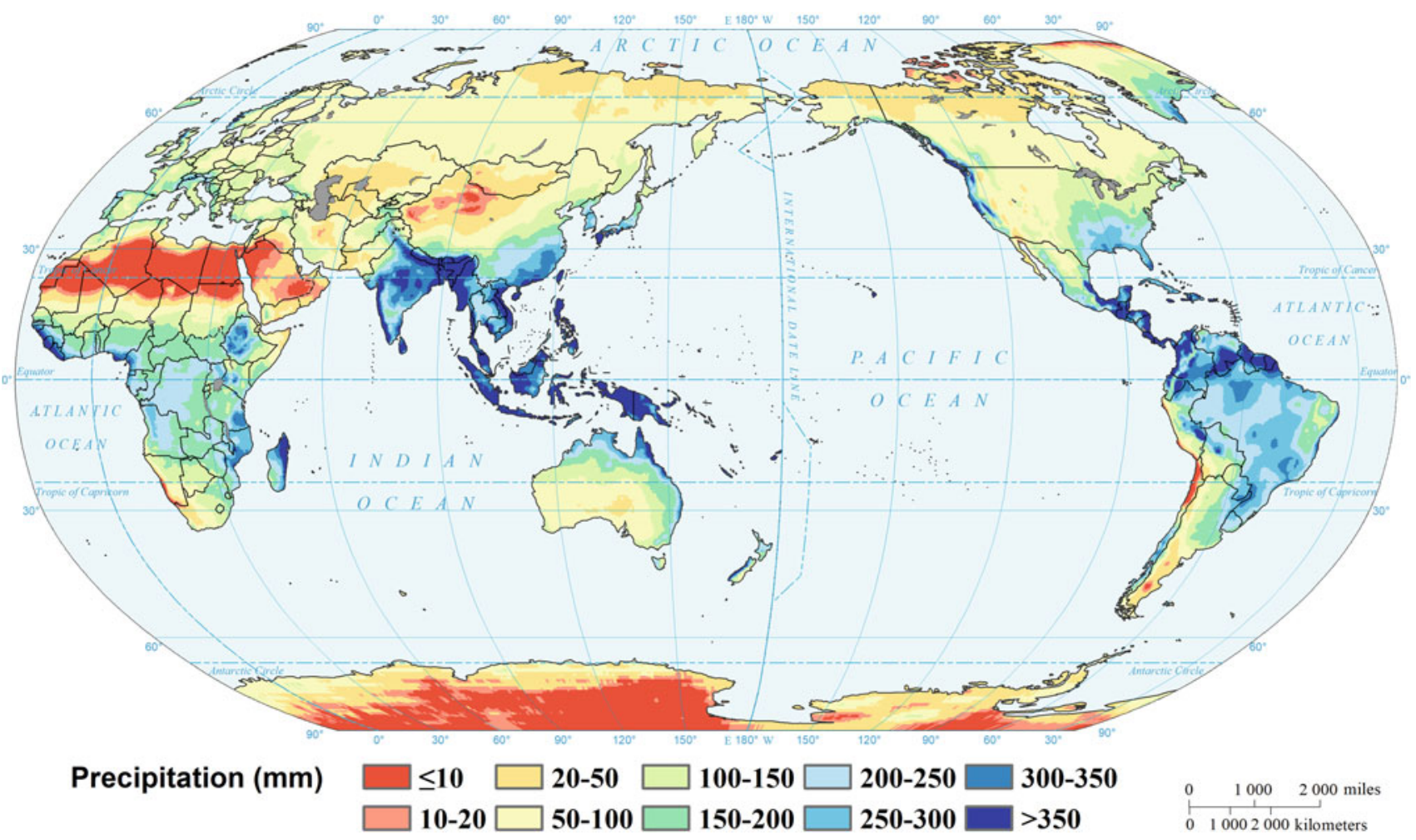


Precipitation variability (2030s, RCP8.5)

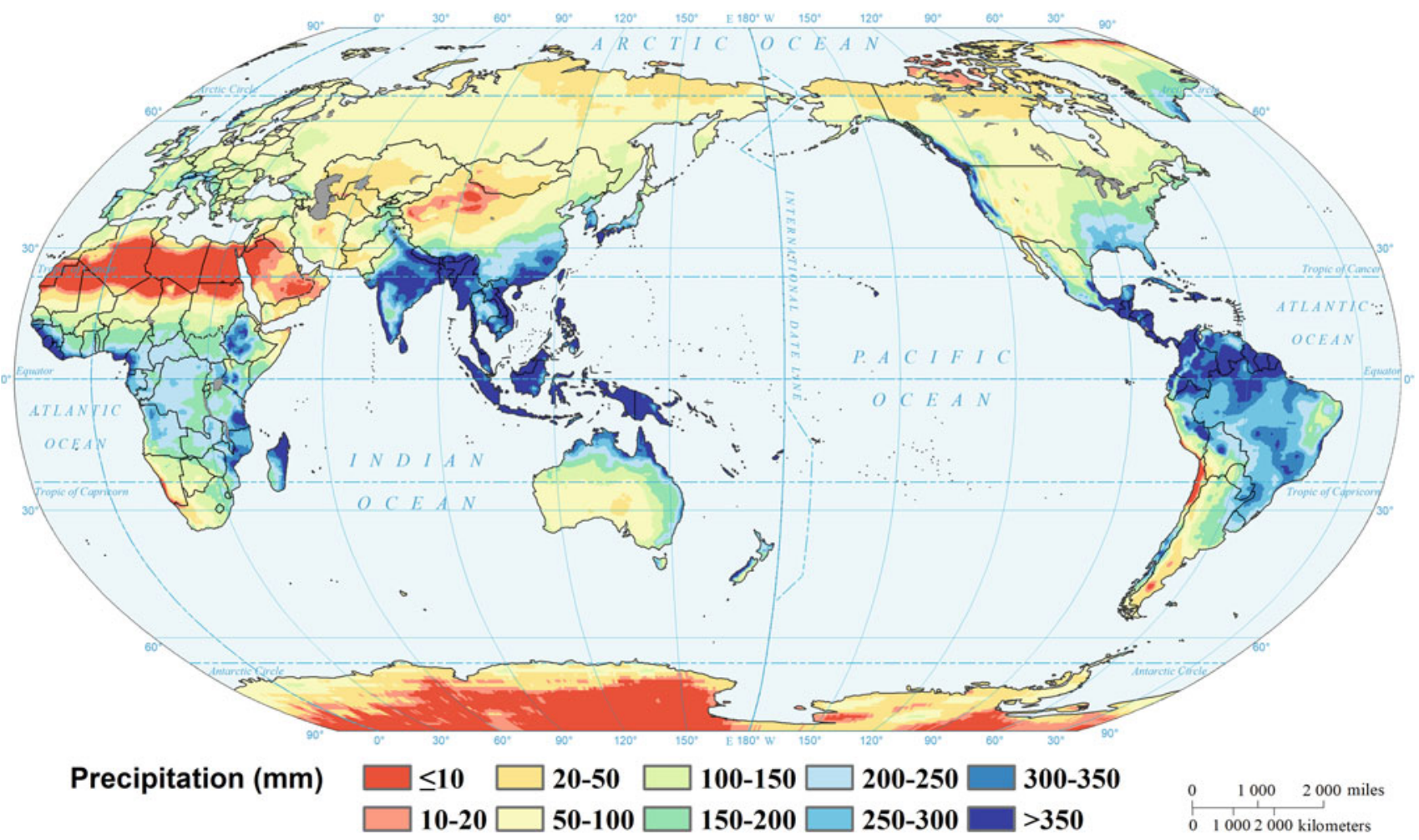

Precipitation variability (2050s, RCP2.6)

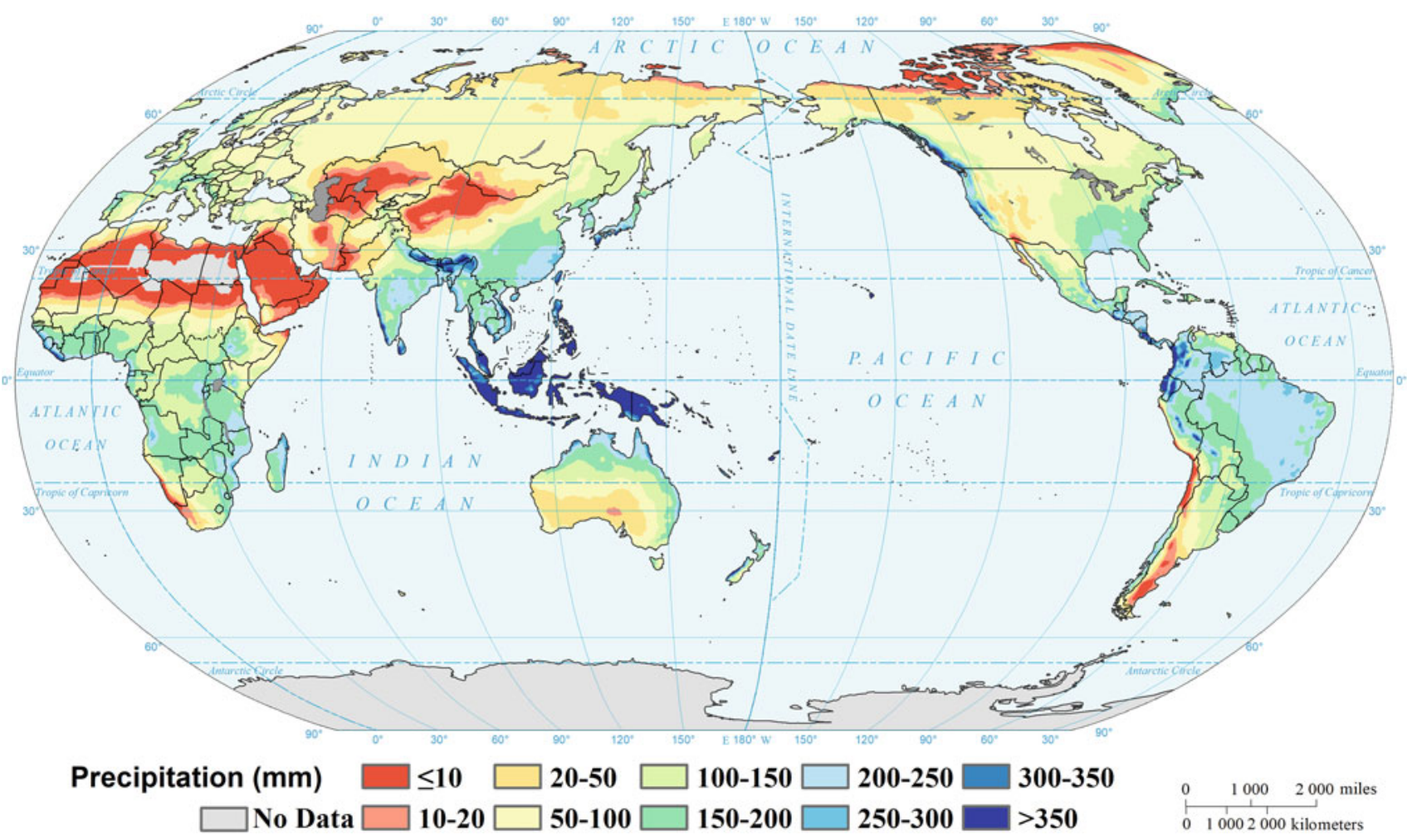


Precipitation variability (2050s, RCP4.5)

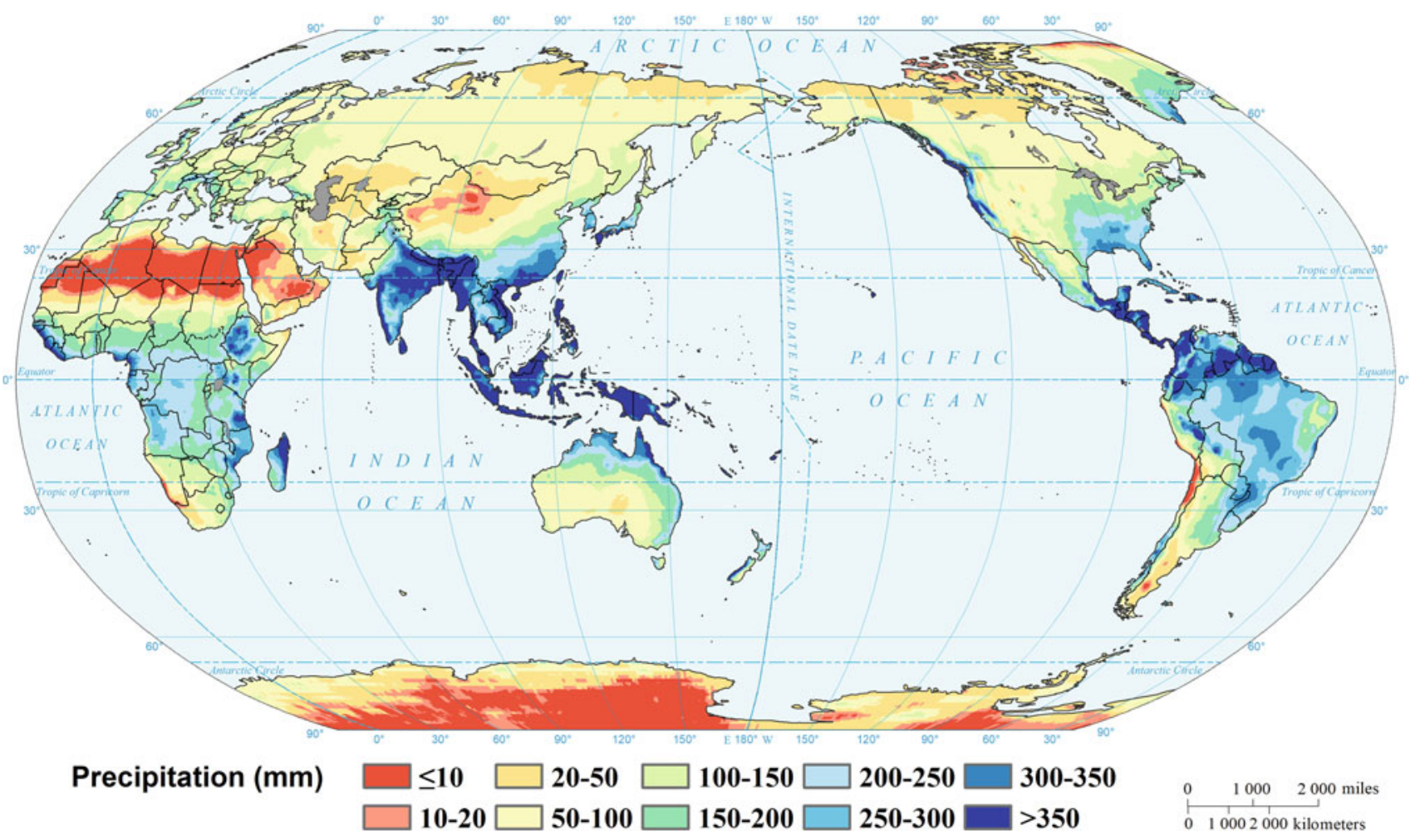

Precipitation variability (2050s, RCP8.5)

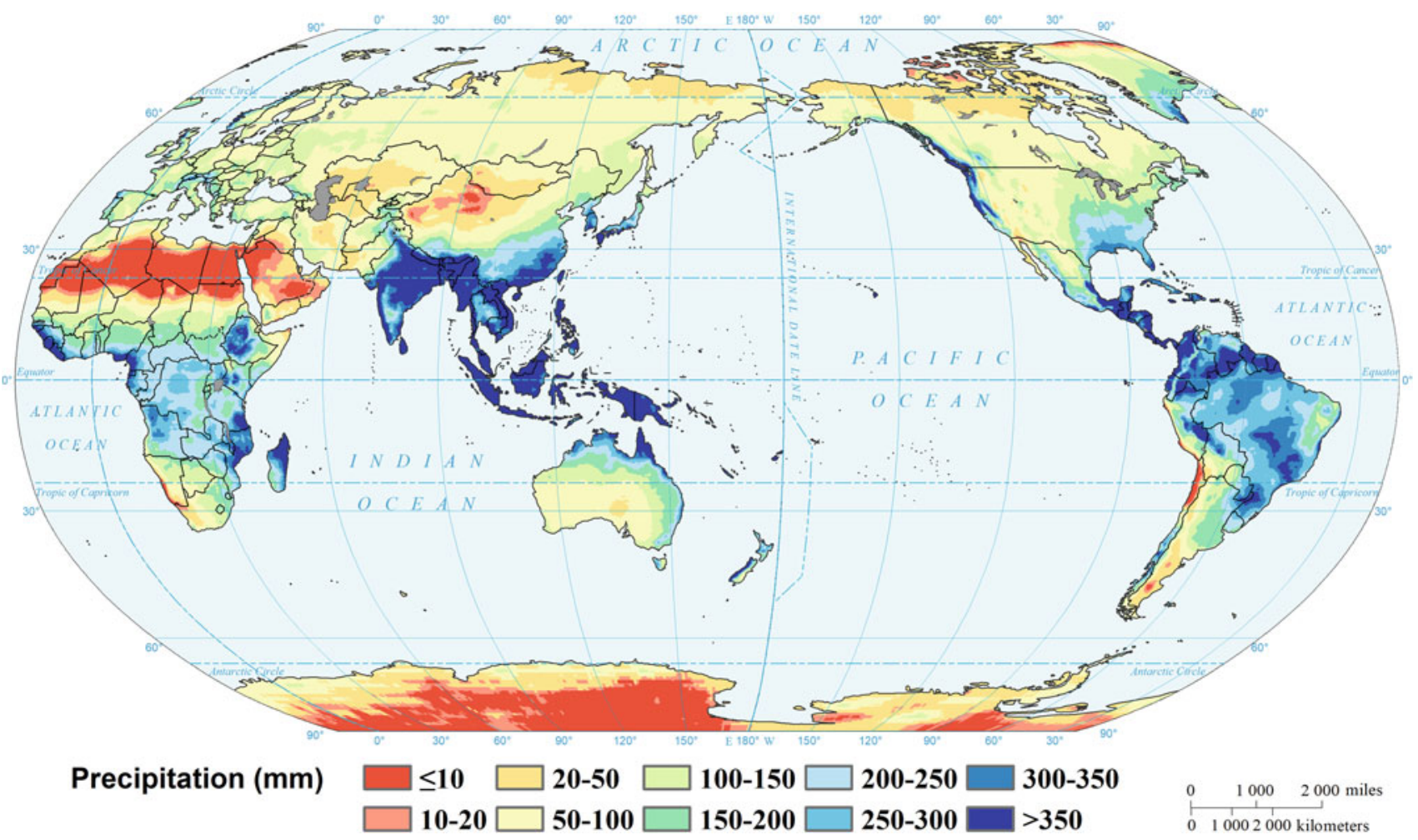




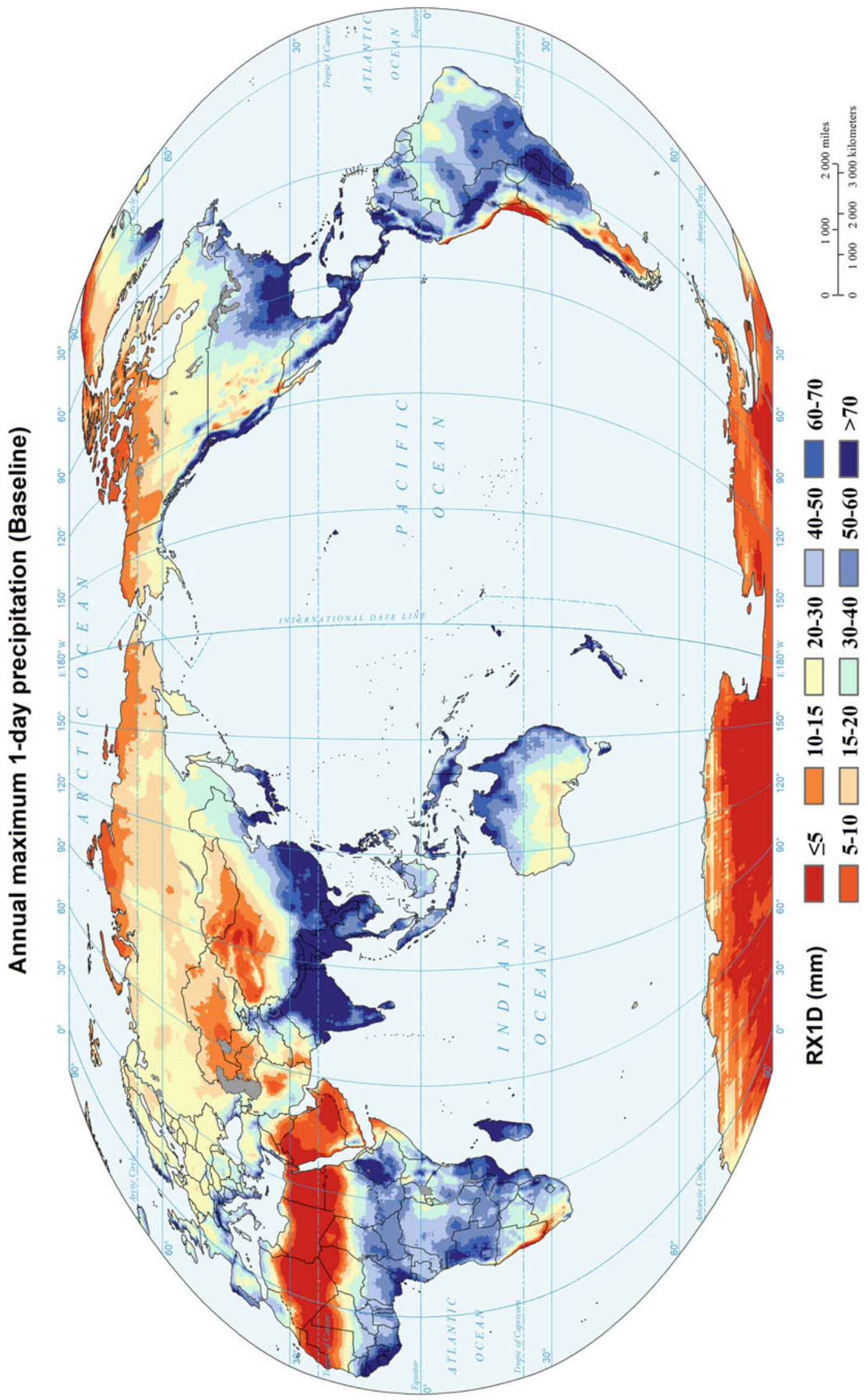


Annual maximum 1-day precipitation (2030s, RCP2.6)

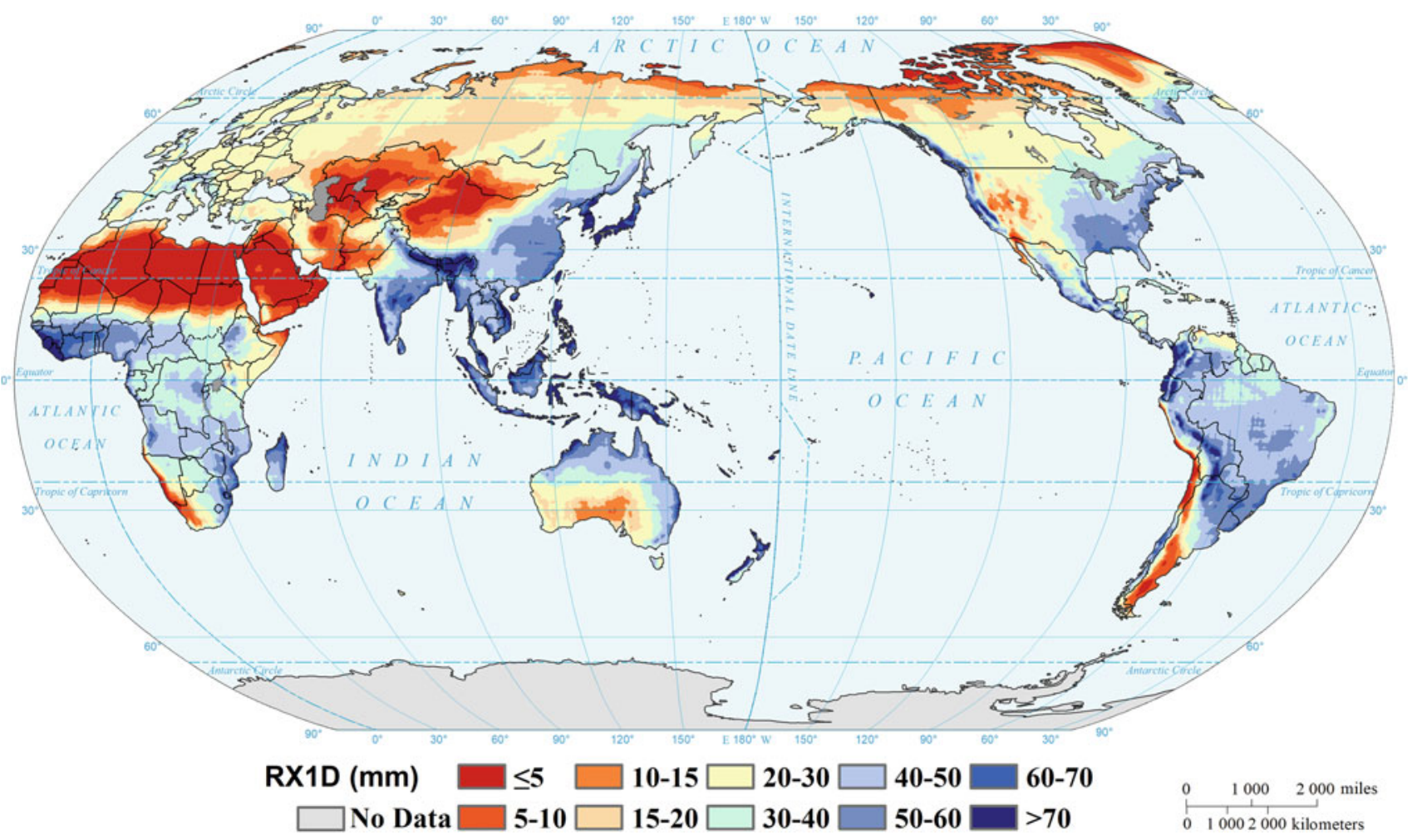

Annual maximum 1-day precipitation (2030s, RCP4.5)

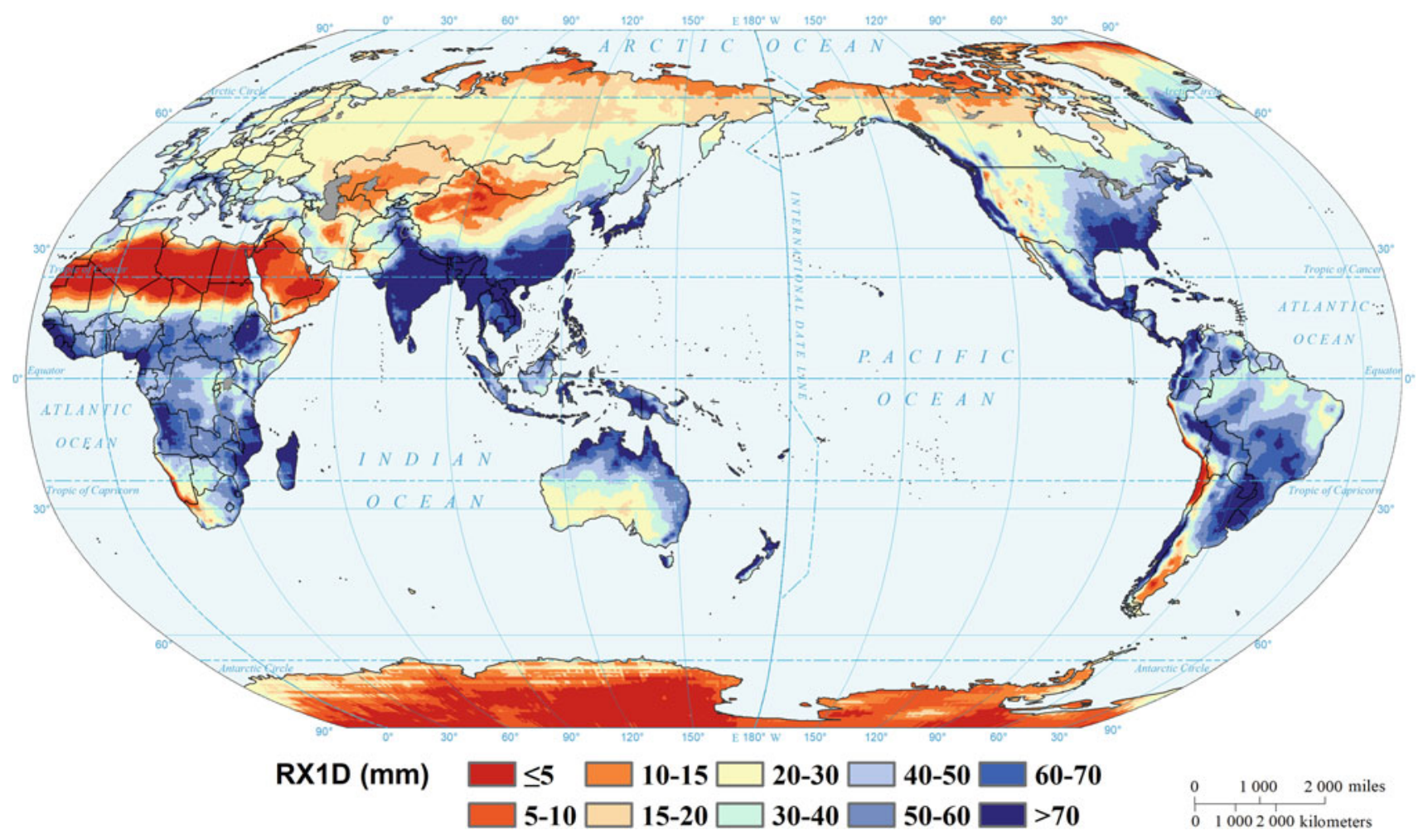


Annual maximum 1-day precipitation (2030s, RCP8.5)

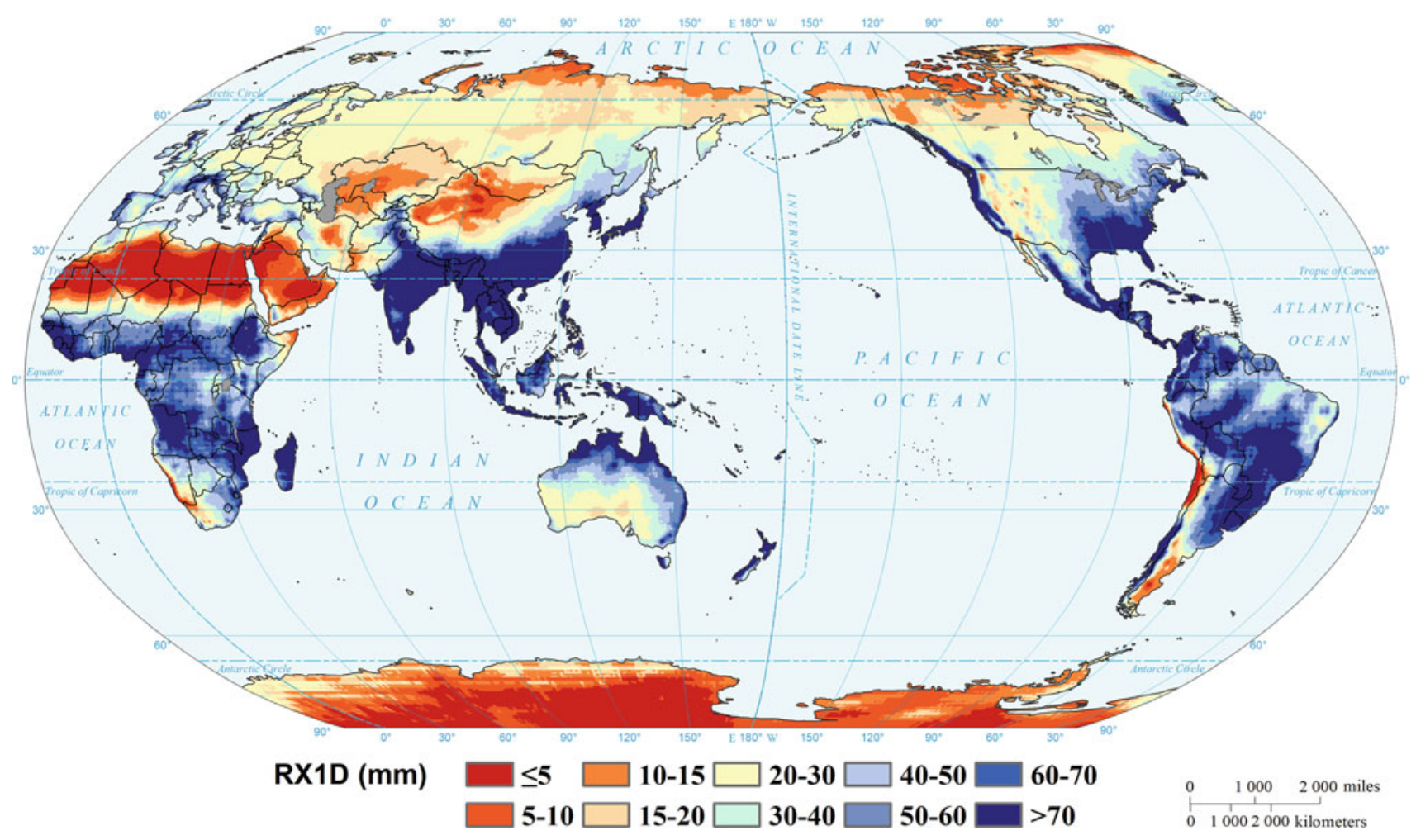

Annual maximum 1-day precipitation (2050s, RCP2.6)

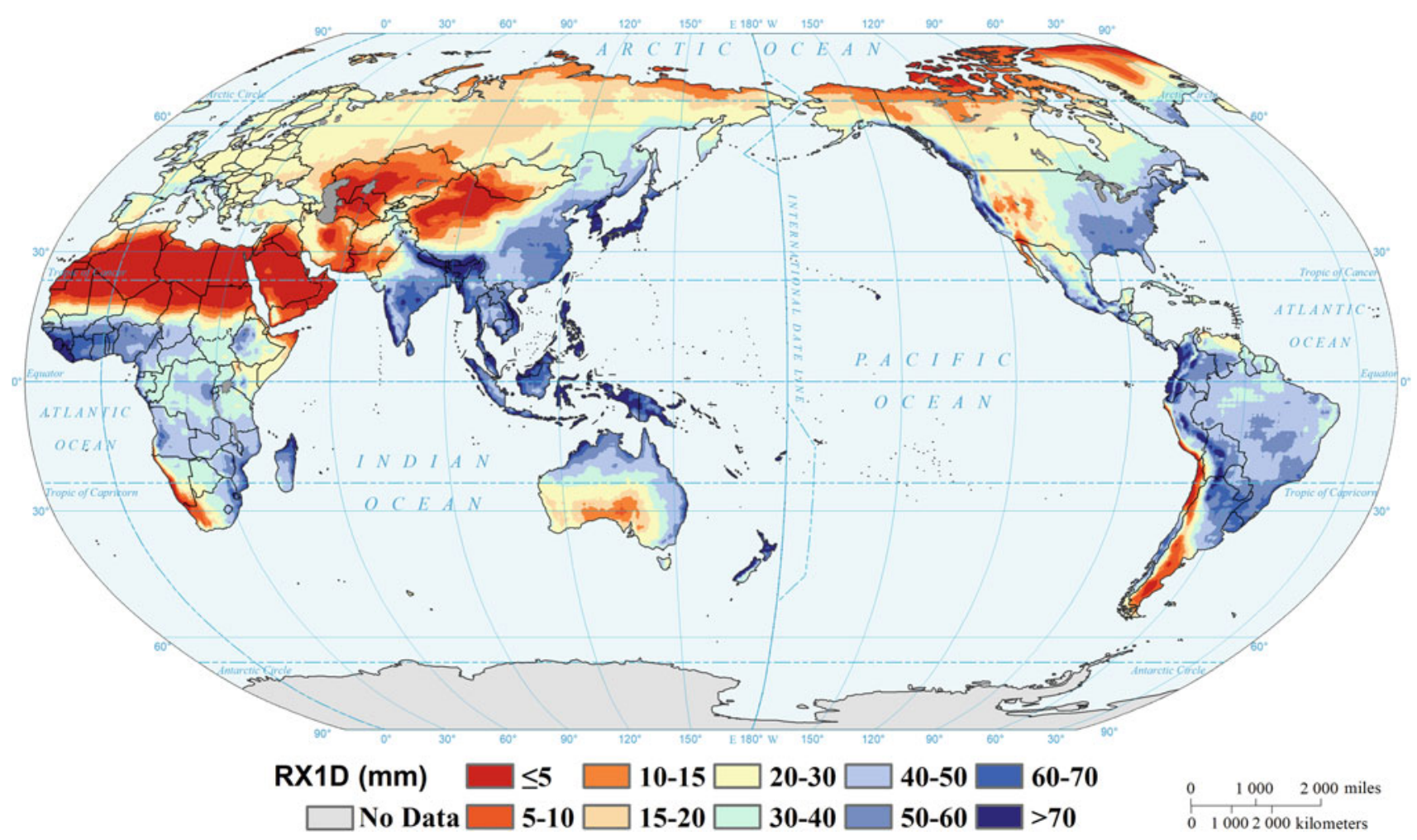


Annual maximum 1-day precipitation (2050s, RCP4.5)

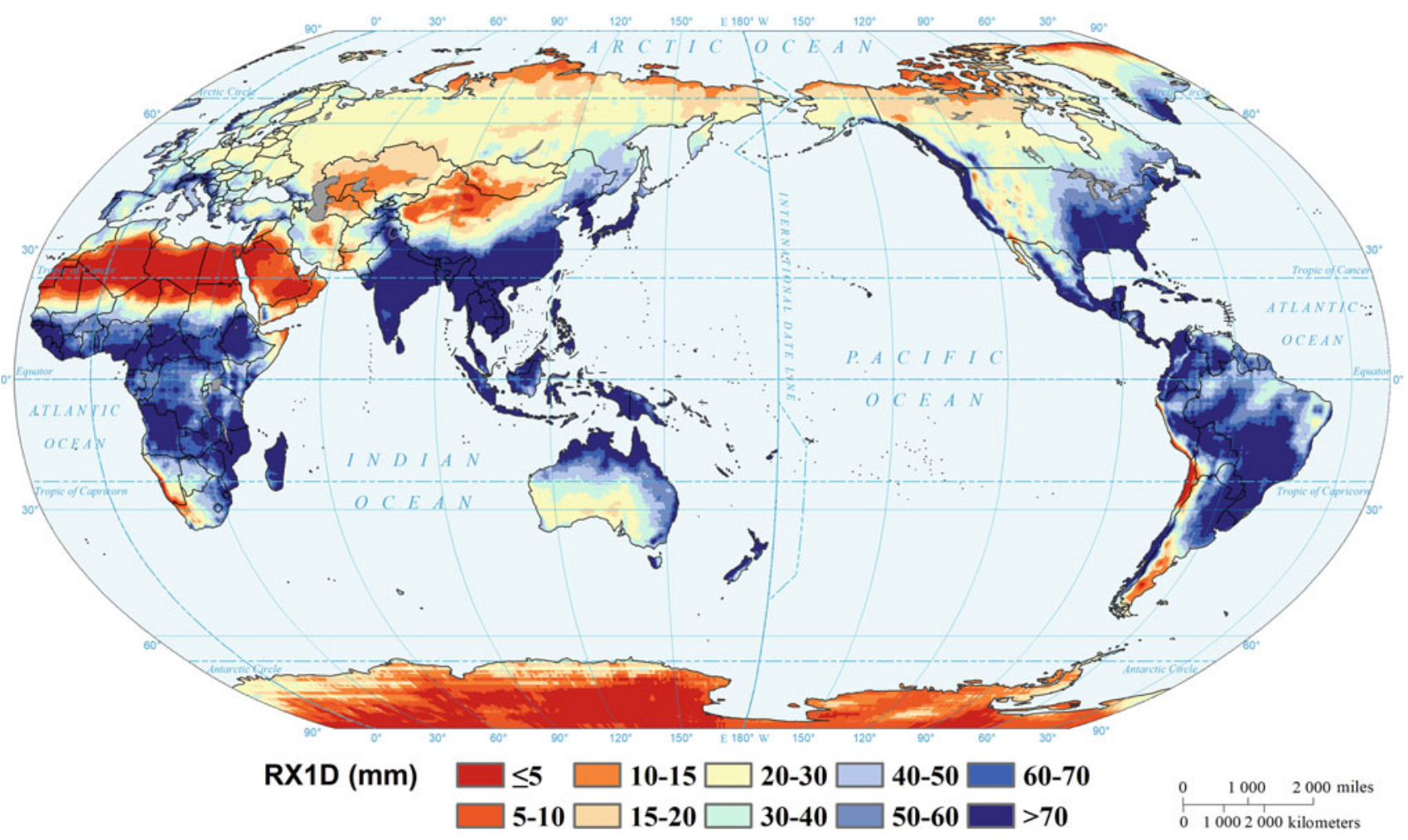

Annual maximum 1-day precipitation (2050s, RCP8.5)

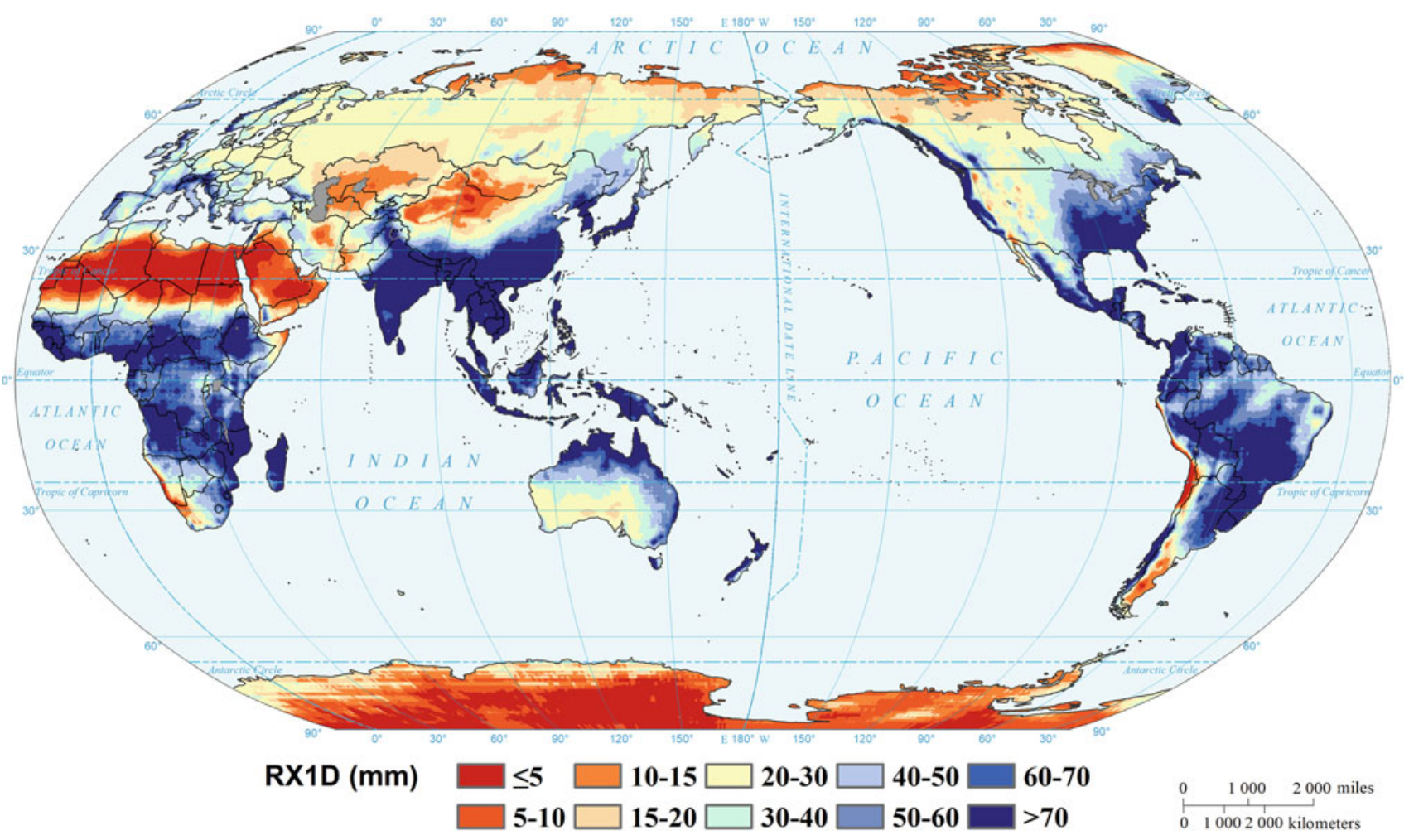




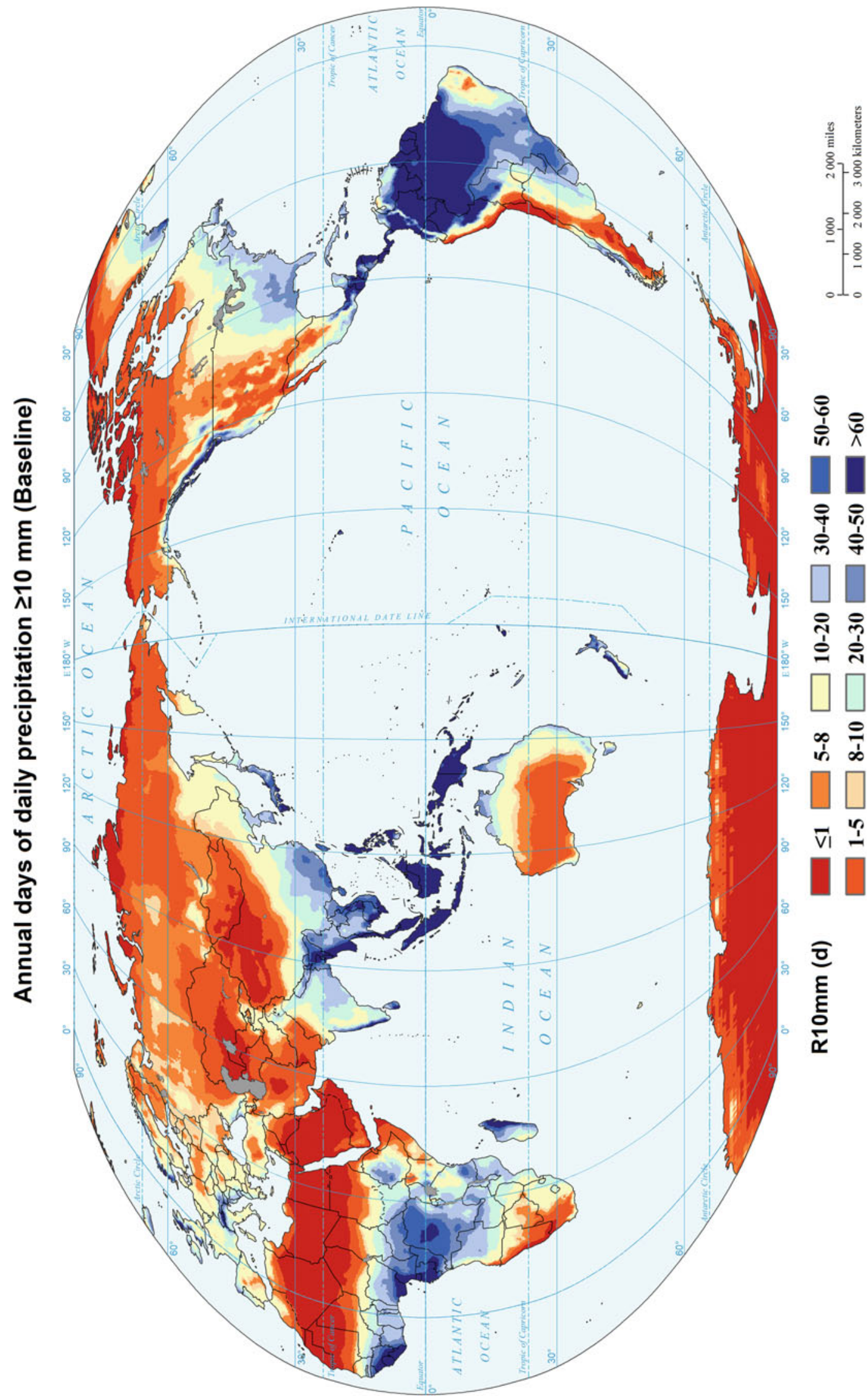


Annual days of daily precipitation $\geq 10 \mathrm{~mm}(2030 \mathrm{~s}, \mathrm{RCP} 2.6)$

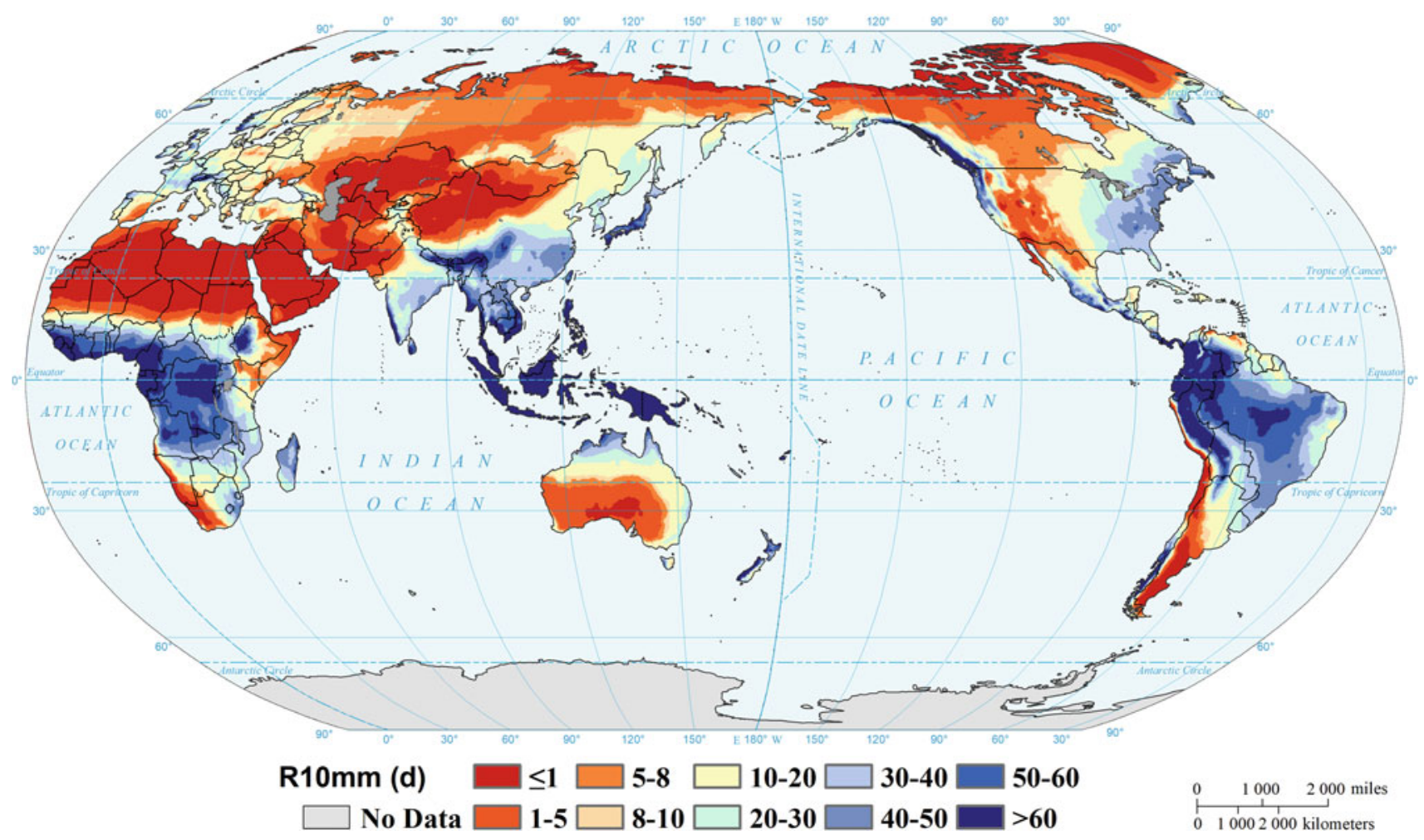

Annual days of daily precipitation $\geq 10 \mathrm{~mm}$ (2030s, RCP4.5)

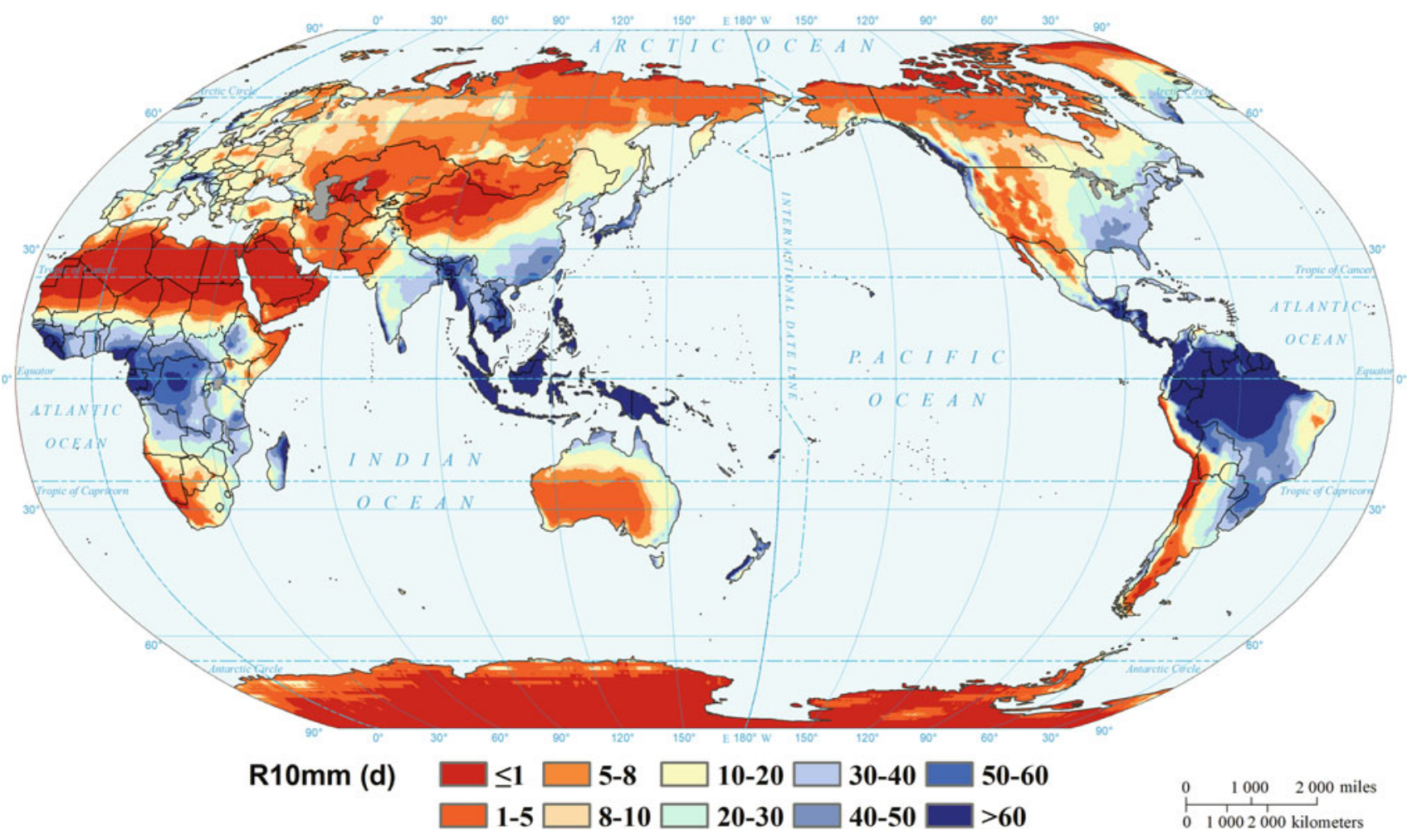


Annual days of daily precipitation $\geq 10 \mathrm{~mm}$ (2030s, RCP8.5)

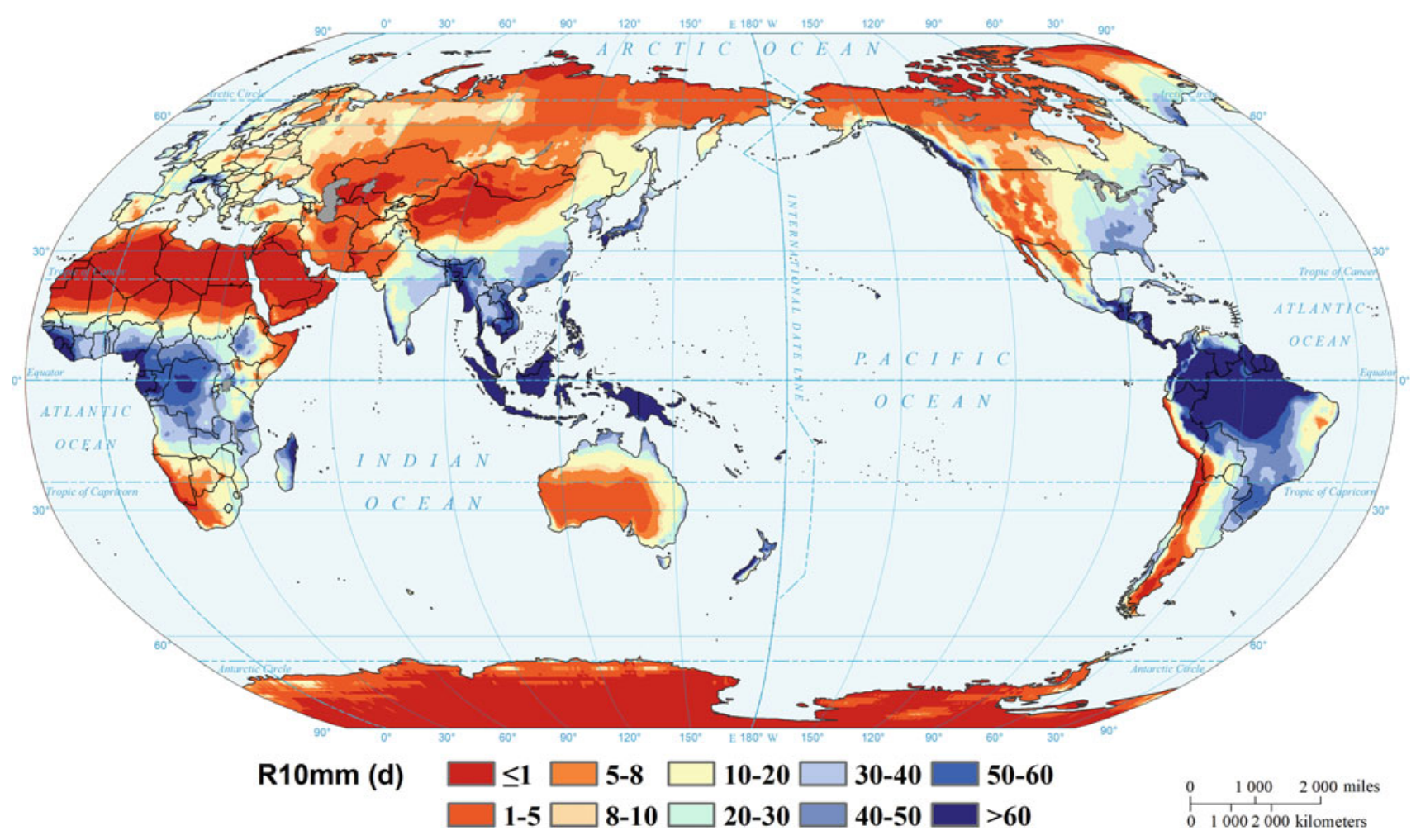

Annual days of daily precipitation $\geq 10 \mathrm{~mm}$ (2050s, RCP2.6)

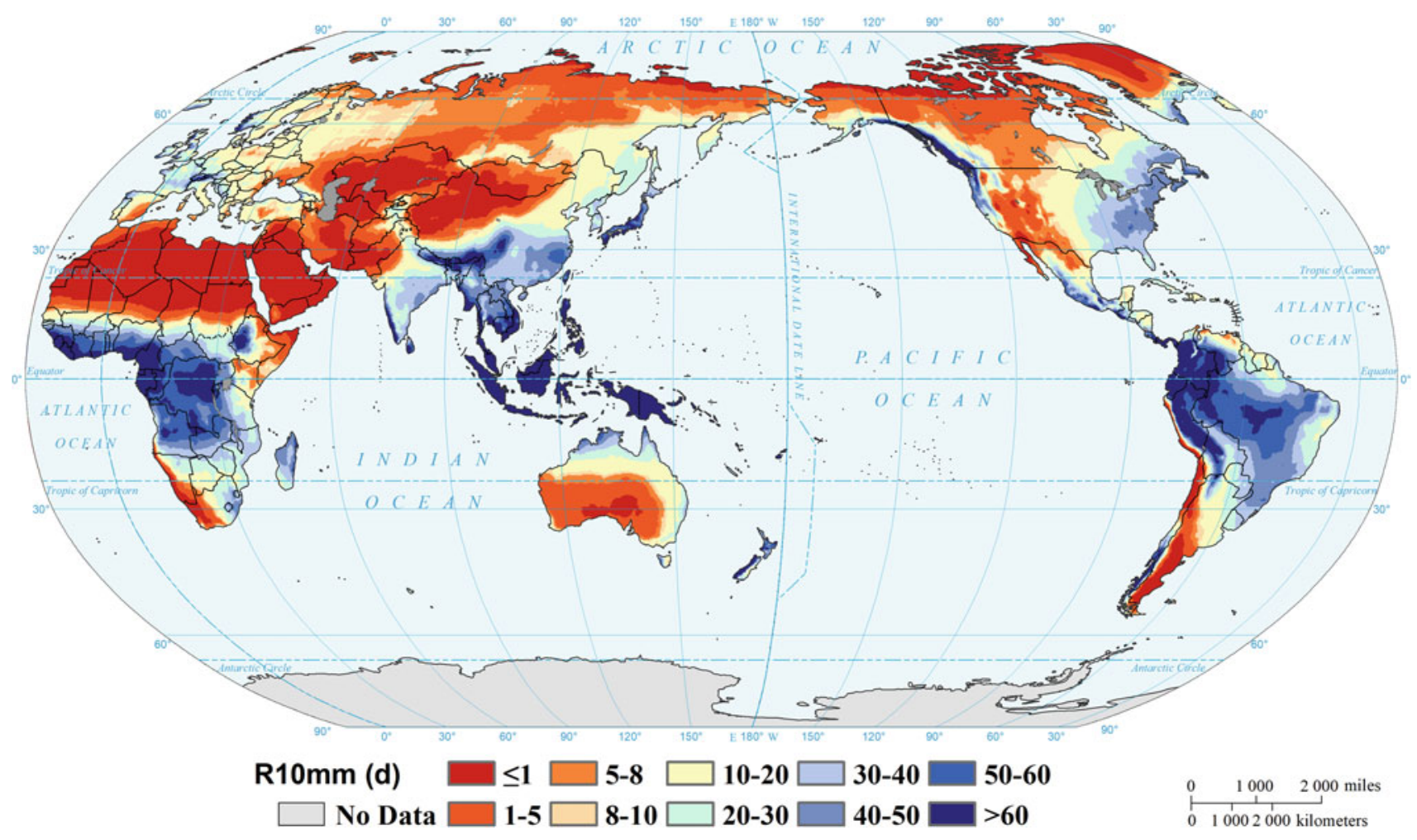


Annual days of daily precipitation $\geq 10 \mathrm{~mm}$ (2050s, RCP4.5)

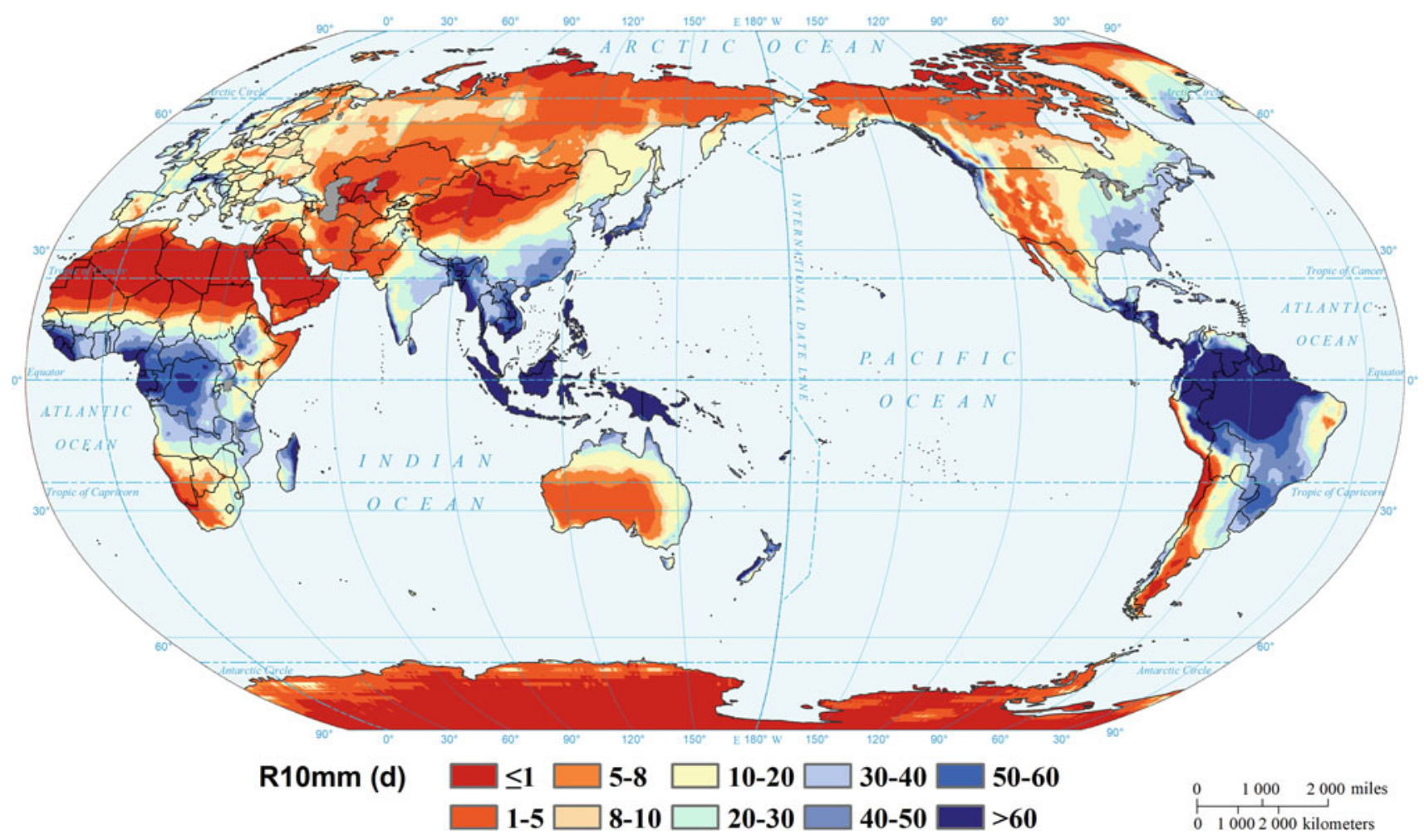

Annual days of daily precipitation $\geq 10 \mathrm{~mm}$ (2050s, RCP8.5)

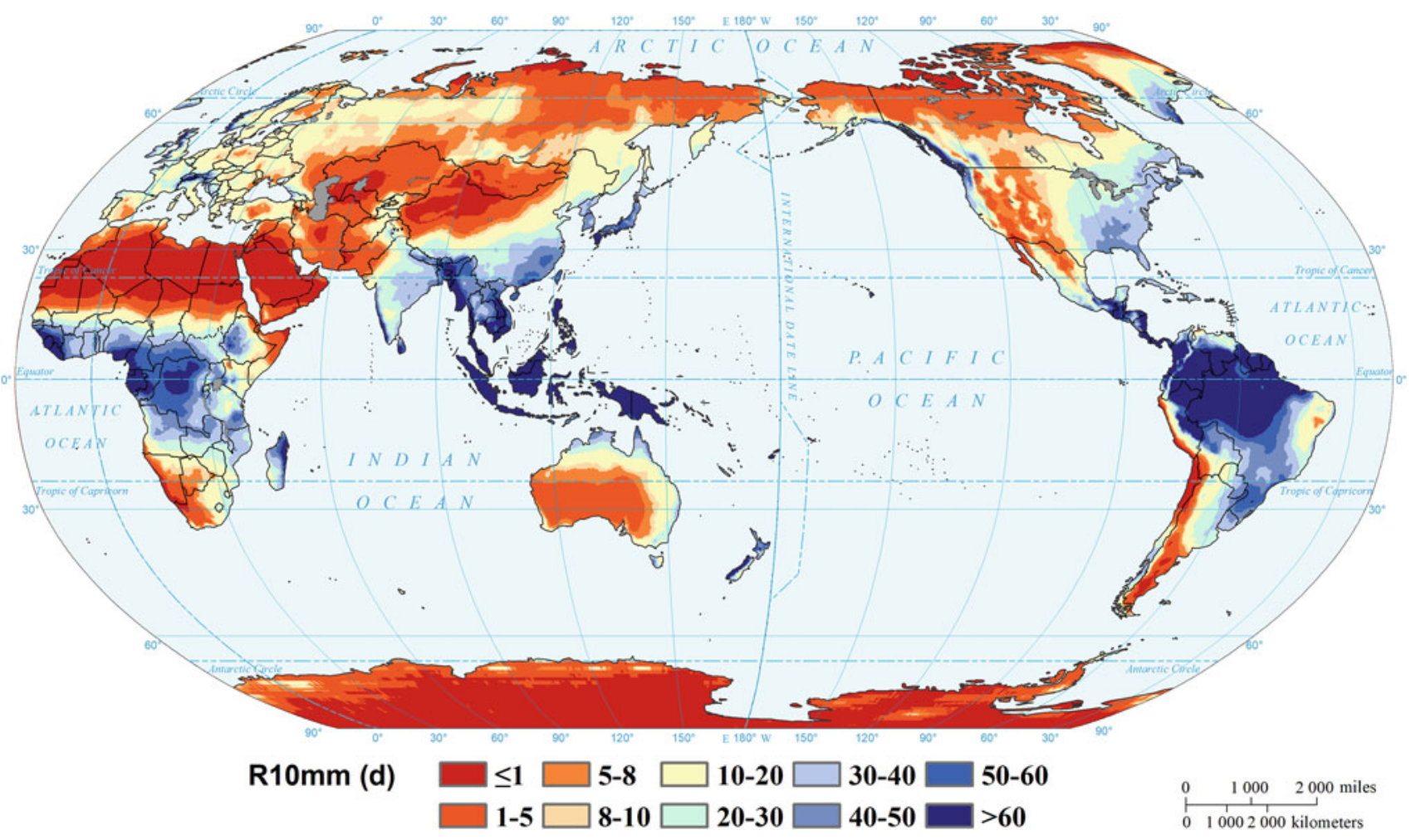




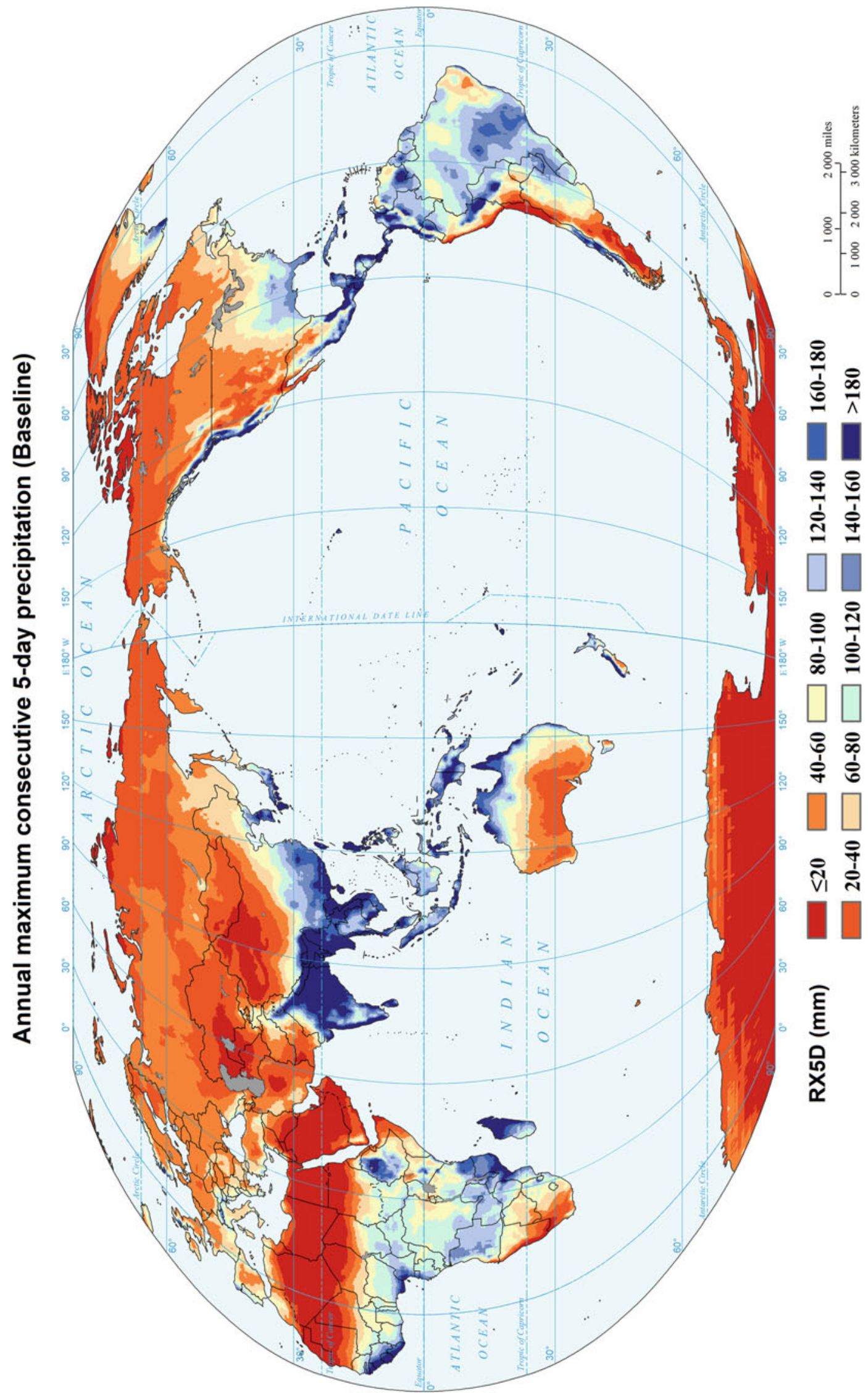


Annual maximum consecutive 5-day precipitation (2030s, RCP2.6)

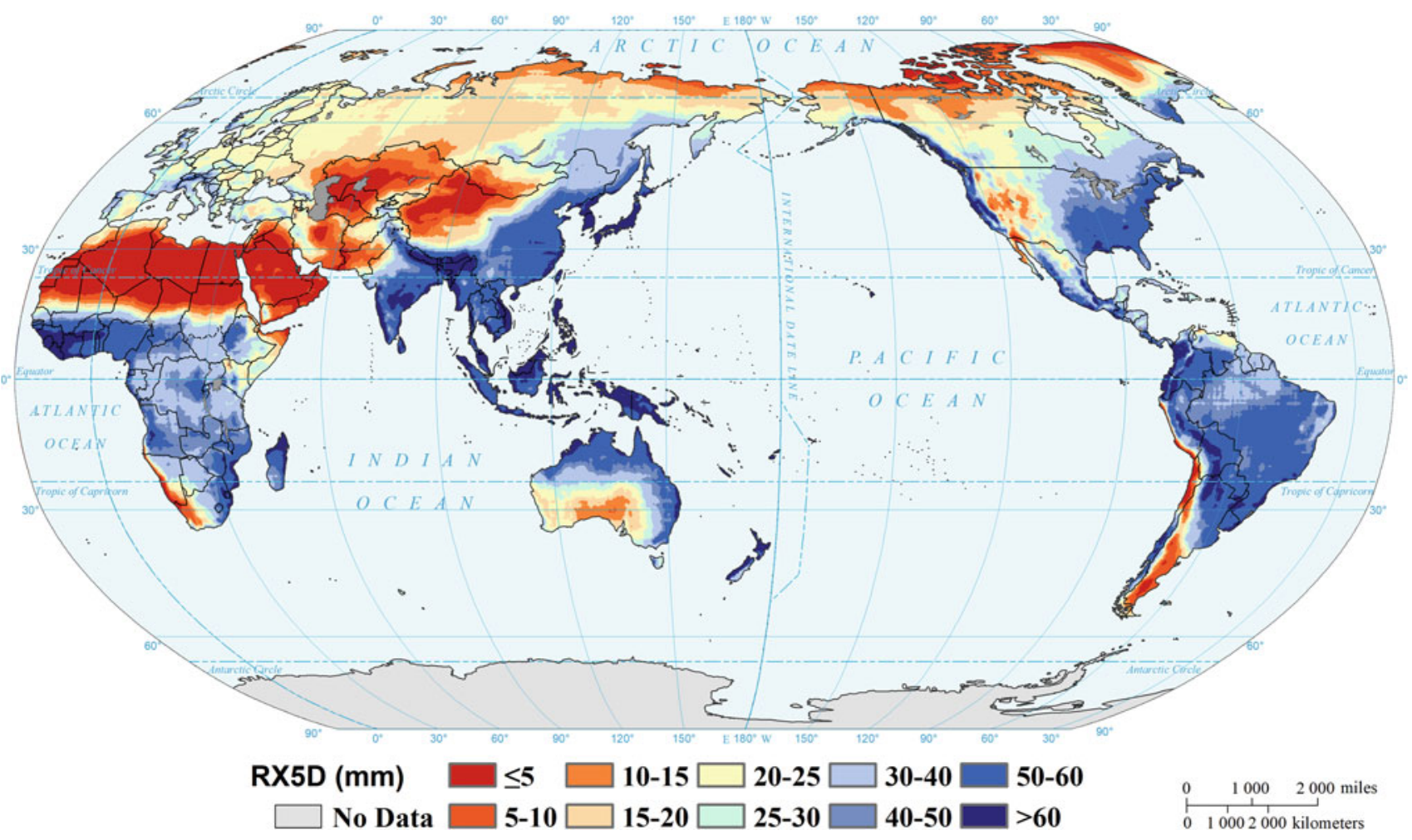

Annual maximum consecutive 5-day precipitation (2030s, RCP4.5)

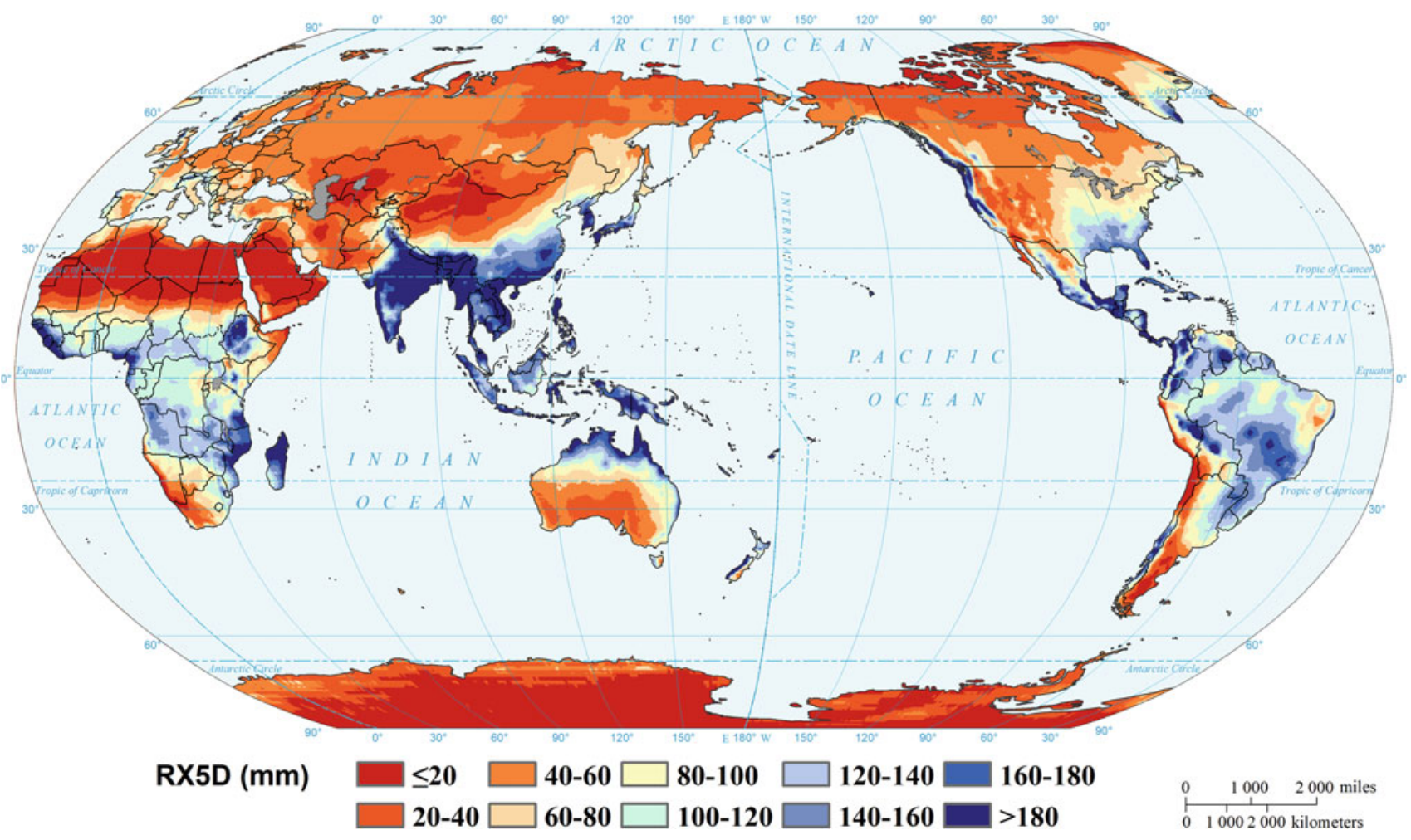


Annual maximum consecutive 5-day precipitation(2030s, RCP8.5)

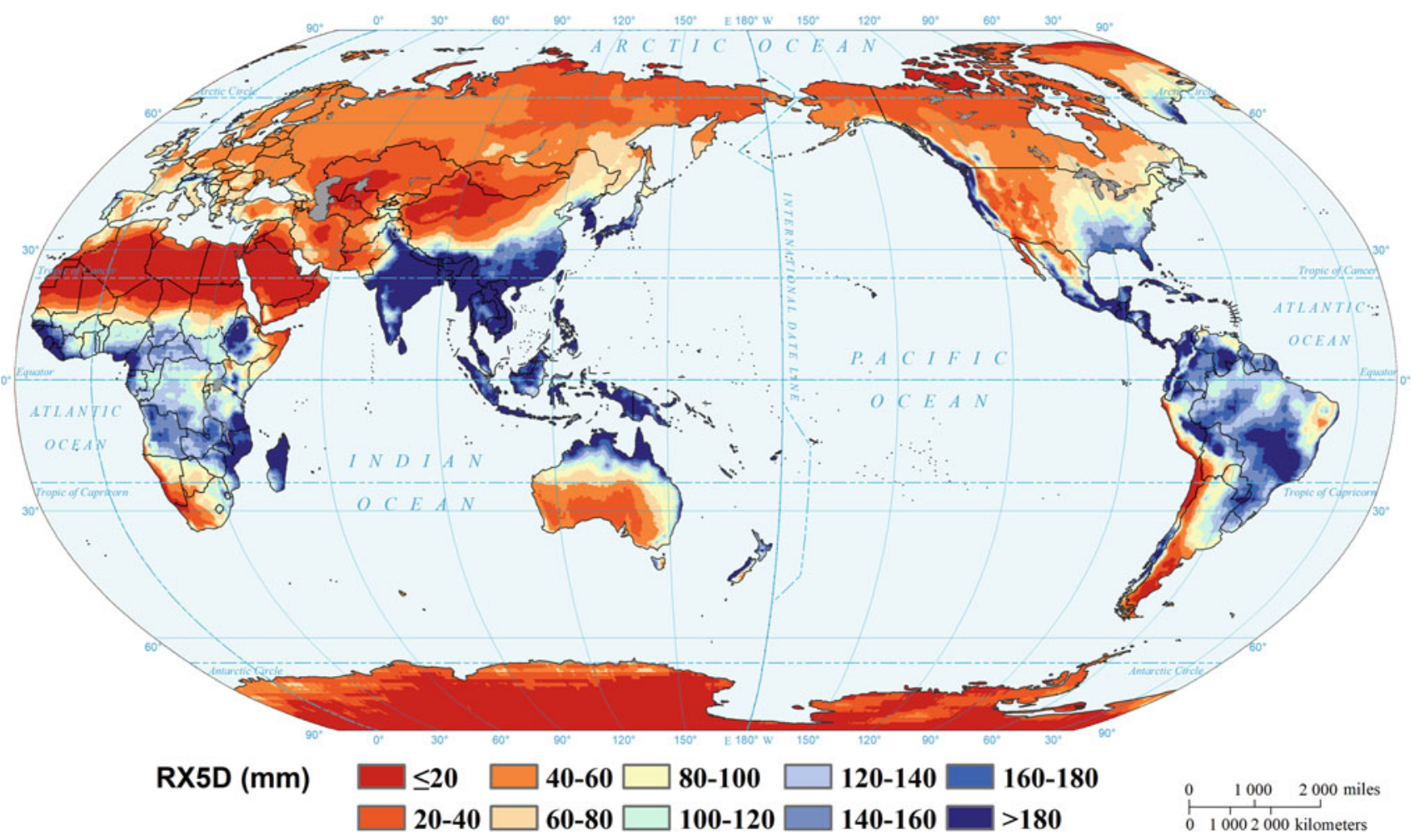

Annual maximum consecutive 5-day precipitation (2050s, RCP2.6)

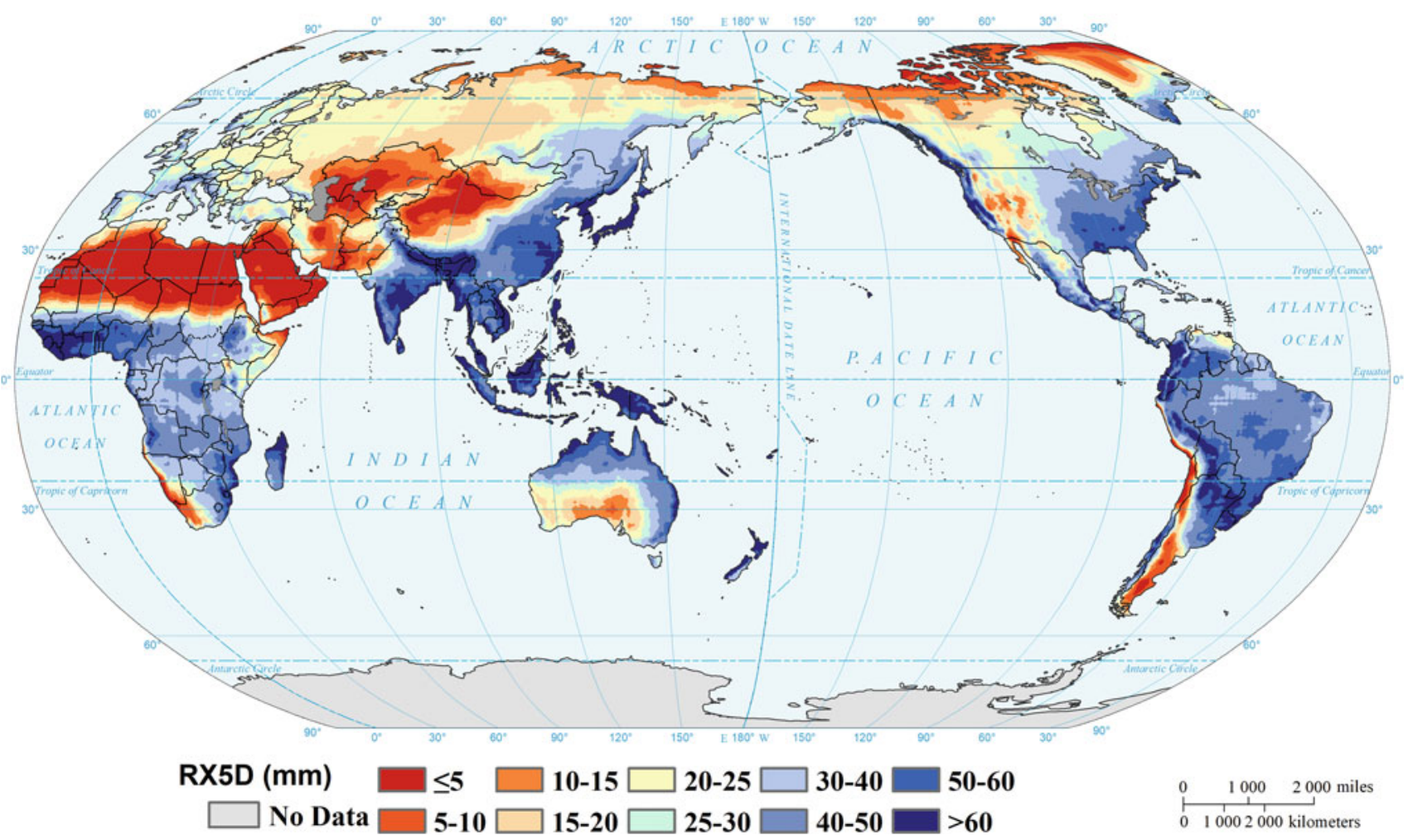


Annual maximum consecutive 5-day precipitation (2050s, RCP4.5)

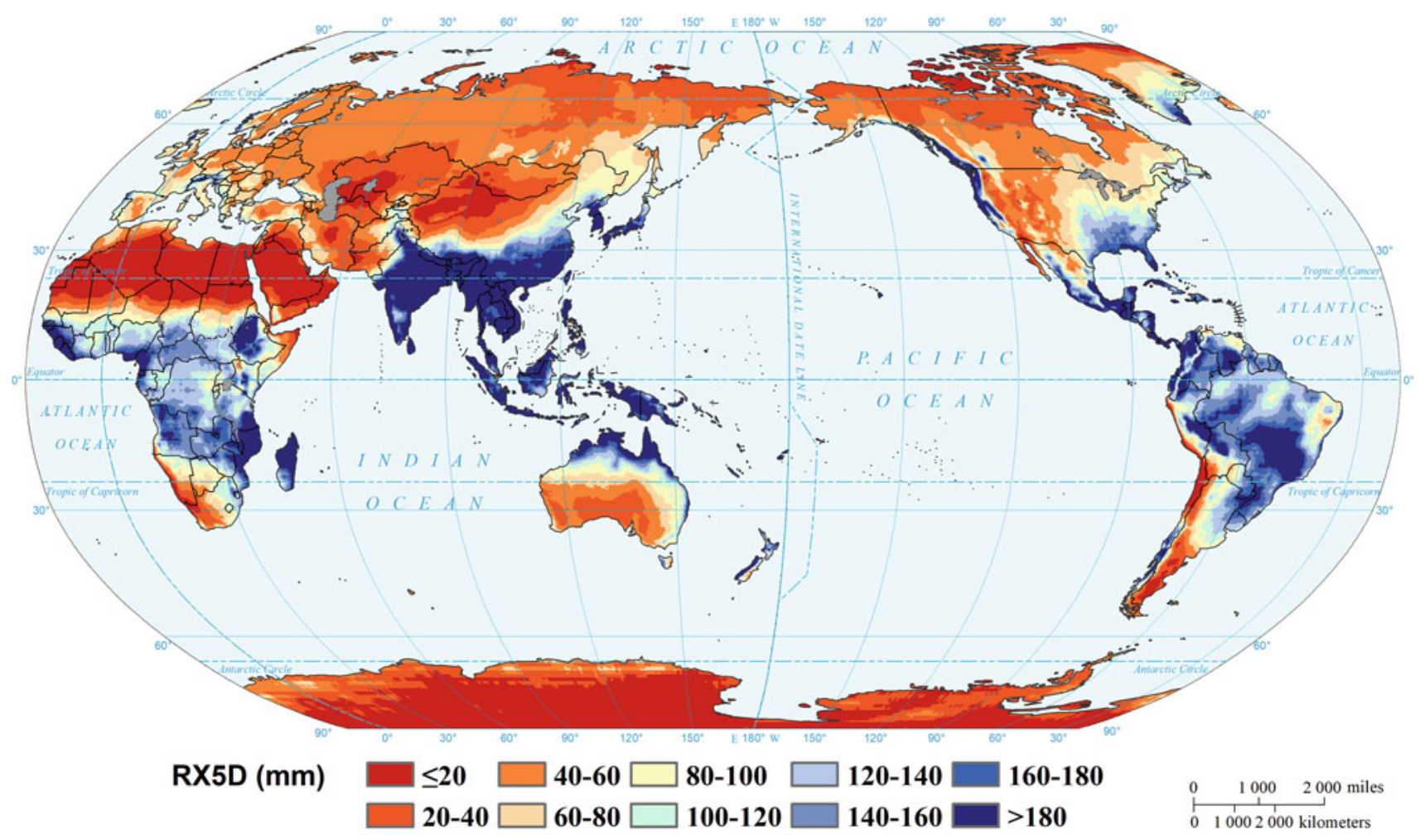

Annual maximum consecutive 5-day precipitation (2050s, RCP8.5)

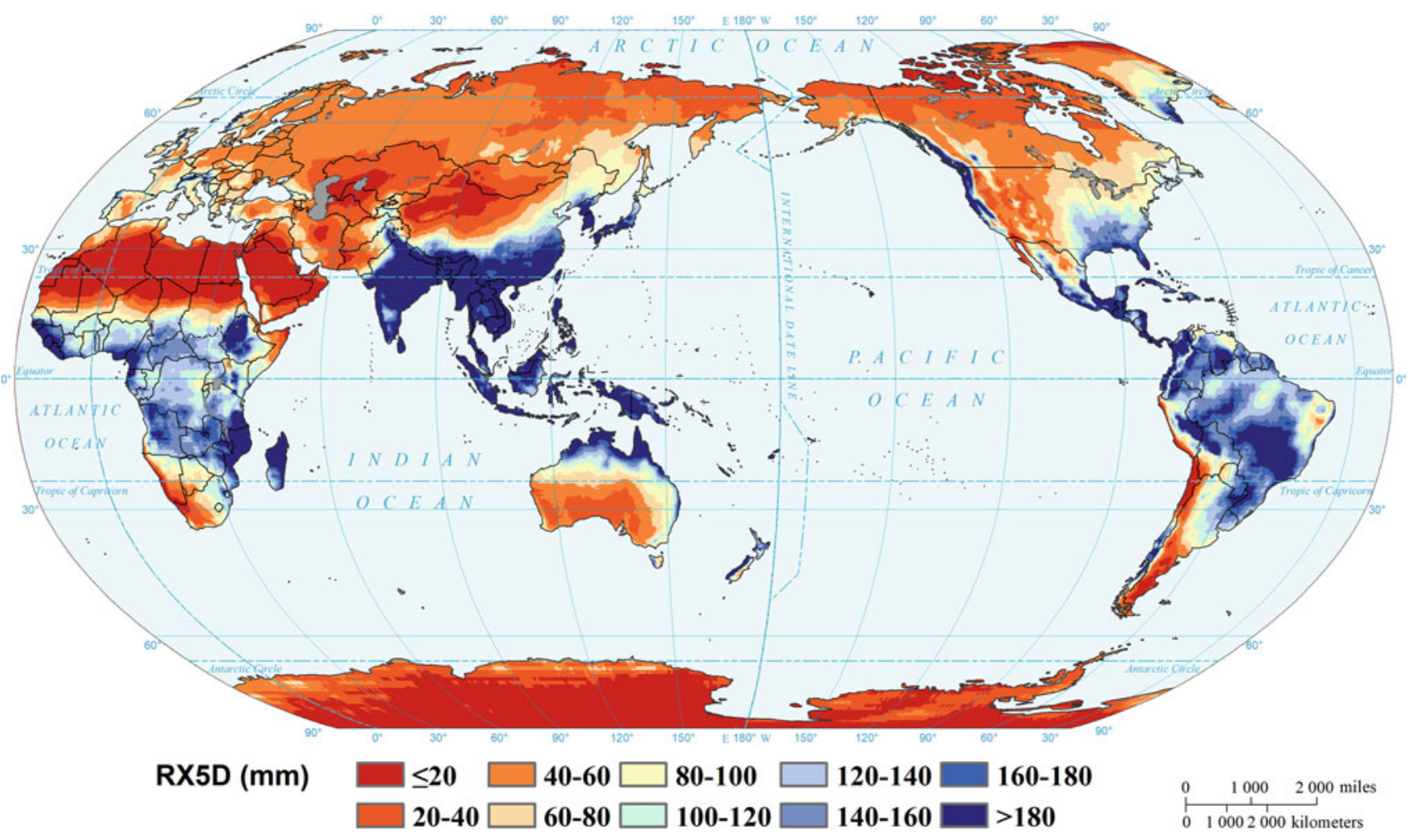




\section{References}

Giorgi, F., and X. Bi. 2005. Regional changes in surface climate interannual variability for the 21 st century from ensembles of global model simulations. Geophysical Research Letters 32: L13701.

Hartmann, D.L., and Coauthors. 2013. Observations: Atmosphere and surface. In Climate Change 2013: The Physical Science Basis. Contribution of Working Group I to the Fifth Assessment Report of the Intergovernmental Panel on Climate Change, ed. T.F. Stocker et al., 159-254. Cambridge, UK: Cambridge University Press.

IPCC. 2013. Climate change 2013: The physical science basis. In Contribution of Working Group I to the Fifth Assessment Report of the Intergovernmental Panel on Climate Change. Cambridge, UK, New York, USA: Cambridge University Press.

Klein Tank, A.M.G., F.W. Zwiers, and X. Zhang. 2009. Guidelines on analysis of extremes in a changing climate in support of informed decisions for adaptation. Climate data and monitoring WCDMP-No. 72, WMO-TD No. 1500.

Weber, T., A. Haensler, D. Rechid, S. Pfeifer, B. Eggert, and D. Jacob. 2018. Analyzing regional climate change in Africa in a 1.5, 2, and 3 degrees C global warming world. Earth's Future 6(4): 643-655.

Xu, L., and A. Wang. 2019. Application of the bias correction and spatial downscaling algorithm on the temperature extremes from CMIP5 multi-model ensembles in China. Earth and Space Science 6 (12): 2508-2524.

Xu, L., A. Wang, D. Wang, and H. Wang. 2019. Hot spots of climate extremes in the future. Journal of Geophysical Research: Atmospheres 124: 3035-3049.

Zhang, X., L. Alexander, G.C. Hegerl, P. Jones, A.K. Tank, T.C. Peterson, B. Trewin, and F.W. Zwiers. 2011. Indices for monitoring changes in extremes based on daily temperature and precipitation data. Wires Climate Change 2: 851-870.
Open Access This chapter is licensed under the terms of the Creative Commons Attribution 4.0 International License (http:// creativecommons.org/licenses/by/4.0/), which permits use, sharing, adaptation, distribution and reproduction in any medium or format, as long as you give appropriate credit to the original author(s) and the source, provide a link to the Creative Commons license and indicate if changes were made.
The images or other third party material in this chapter are included in the chapter's Creative Commons license, unless indicated otherwise in a credit line to the material. If material is not included in the chapter's Creative Commons license and your intended use is not permitted by statutory regulation or exceeds the permitted use, you will need to obtain permission directly from the copyright holder. 